\title{
The Diurnal Cycle of Rainfall and Convective Intensity according to Three Years of TRMM Measurements
}

\author{
STEPHEN W. NeSbitT AND EdWARd J. ZiPSER \\ Department of Meteorology, University of Utah, Salt Lake City, Utah
}

(Manuscript received 28 May 2002, in final form 18 September 2002)

\begin{abstract}
The Tropical Rainfall Measuring Mission (TRMM) satellite measurements from the precipitation radar and TRMM microwave imager have been combined to yield a comprehensive 3-yr database of precipitation features (PFs) throughout the global Tropics $\left( \pm 36^{\circ}\right.$ latitude). The PFs retrieved using this algorithm (which number nearly six million Tropicswide) have been sorted by size and intensity ranging from small shallow features greater than $75 \mathrm{~km}^{2}$ in area to large mesoscale convective systems (MCSs) according to their radar and ice scattering characteristics. This study presents a comprehensive analysis of the diurnal cycle of the observed precipitation features' rainfall amount, precipitation feature frequency, rainfall intensity, convective-stratiform rainfall portioning, and remotely sensed convective intensity, sampled Tropicswide from space.

The observations are sorted regionally to examine the stark differences in the diurnal cycle of rainfall and convective intensity over land and ocean areas. Over the oceans, the diurnal cycle of rainfall has small amplitude, with the maximum contribution to rainfall coming from MCSs in the early morning. This increased contribution is due to an increased number of MCSs in the nighttime hours, not increasing MCS areas or conditional rain rates, in agreement with previous works. Rainfall from sub-MCS features over the ocean has little appreciable diurnal cycle of rainfall or convective intensity. Land areas have a much larger rainfall cycle than over the ocean, with a marked minimum in the midmorning hours and a maximum in the afternoon, slowly decreasing through midnight. Non-MCS features have a significant peak in afternoon instantaneous conditional rain rates (the mean rain rate in raining pixels), and convective intensities, which differs from previous studies using rain rates derived from hourly rain gauges. This is attributed to enhancement by afternoon heating. MCSs over land have a convective intensity peak in the late afternoon, however all land regions have MCS rainfall peaks that occur in the late evening through midnight due to their longer life cycle. The diurnal cycle of overland MCS rainfall and convective intensity varies significantly among land regions, attributed to MCS sensitivity to the varying environmental conditions in which they occur.
\end{abstract}

\section{Introduction}

Our physical understanding of the diurnal cycle of precipitation and convective intensity is currently limited by our ability to observe and model the cycle itself. The same processes that govern the physics of clouds in general fundamentally dictate the diurnal modulation of precipitating systems. Despite this fact, our comprehension of the fundamental controlling physical mechanisms remains deficient. Limitations revolve around two fundamental issues: 1) our inability to observe and quantify the true Tropicswide diurnal cycle of rainfall amount and convective intensity, and 2) the use of numerical model simulations that may have deficiencies that do not allow the true representation of the diurnal cycle. The first limitation has been caused by incomplete sampling and/or the use of indirect proxies for rainfall

Corresponding author address: Stephen W. Nesbitt, Department of Atmospheric Science, Colorado State University, Fort Collins, CO 80523-1371.

E-mail: snesbitt@atmos.colostate.edu that substitute for the measurement of the quantities of interest. The second limitation above also suffers from our lack, until recently, of complete and comprehensive observational datasets that can be used to validate our conceptual and numerical models.

\section{Mechanisms behind the diurnal cycle}

Most previous works comparing the tropical rainfall diurnal cycle over ocean and land surfaces agree that the amplitude of the diurnal cycle of rainfall over continents is larger than that over the open oceans (Gray and Jacobson 1977). However, studies conducted over different regions of the Tropics have found significant differences in the character of the diurnal cycle, leading to different hypothesized causal mechanisms. Over land, many studies using surface rain accumulation (Wallace 1975; Gray and Jacobson 1977; Oki and Musiake 1994; Dai et al. 1999) and surface weather reports of precipitation frequency (Dai 2001) link the timing of the diurnal precipitation frequency maximum to afternoon 
boundary layer destabilization caused by daytime insolation. However, many studies note that there are land areas with midnight to early morning maxima of precipitation, which may be linked to local effects such as complex terrain and sea-breeze circulations (Oki and Musiake 1994; Yang and Slingo 2000), or the long, nocturnal life cycle of mesoscale convective systems (MCSs; Wallace 1975; McAnelly and Cotton 1989; Dai et al. 1999; Sherwood and Wahrlich 1999).

Despite being smaller in amplitude than over land areas, a substantial oceanic nocturnal maximum of precipitation has been shown by many studies of rain gauge accumulations (Gray and Jacobson 1977) and surface weather reports (Kraus 1963; Dai 2001), which generally agree with studies using proxies for surface rainfall like ground-based radars (Rickenbach 1996; Short et al. 1997) infrared (Short and Wallace 1980; Albright et al. 1985; Hall and Vonder Harr 1999; Chen and Houze 1997; Garreaud and Wallace 1997; Yang and Slingo 2001; Zudiema 2003) and microwave brightness temperatures (Chang et al. 1995; Imaoka and Spencer 2000). However, regional differences in the rainfall diurnal cycle exist over the ocean also. Albright et al. (1985) found an afternoon maximum in cold cloud coverage in the South Pacific convergence zone (SPCZ), while McGarry and Reed (1978) and Reed and Jaffe (1981) show afternoon maxima over the western Atlantic Ocean near the African coast. Near-continent variations in the diurnal cycle have been linked to coastline effects and gravity wave forcing by the nearby continental diurnal cycle (Silva Dias et al. 1987; Yang and Slingo 2001).

Away from the influence of continents, the cause for the observed diurnal cycle of precipitation over the open ocean remains debatable, not well known, and currently under discussion. One mechanism, first proposed by Gray and Jacobson (1977), emphasizes the dynamical consequence of the differential radiative heating between the convective and surrounding cloud-free region producing a daily variation in the horizontal divergence field, modulating the convection. A second mechanism (e.g., Cox and Griffith 1979; Webster and Stephens 1980; Randall et al. 1991) explains the afternoon minimum of oceanic precipitation through the absorption of shortwave radiation by the upper portions of the convective anvils, which increases the static stability in the cloudy regions, weakening vertical motions. Conversely, longwave cooling at night decreases the stability, leading to enhanced convection. A third mechanism may be that nighttime longwave cooling may increase relative humidites sufficiently everywhere that the effects of entrainment are reduced, and cloud development is favored at night (Dudhia 1989; Tao et al. 1996; Dai 2001). A fourth, more complex mechanism is linked to the daily variations in the surface layer over the ocean; Sui et al. (1997) and Chen and Houze (1997) show that an afternoon maximum in ocean skin temperature corresponds with the generation of new convection in the calm Pacific warm pool region. A minimum in convection follows the next day in the convective wakes due to depletion of the local moist static energy and shading of the ocean from shortwave fluxes. Atmospheric tides have also been discussed as a diurnal modulator of lowlevel convergence and rainfall (Malkus 1964; Brier and Simpson 1969; Dai 2001), however Lindzen (1978) has shed doubt on this hypothesis.

None of these mechanisms are necessarily exclusive in acting to modulate the diurnal cycle, making it difficult to separate them in an observational dataset. $\mathrm{Nu}$ merical model studies using cloud resolving models (e.g., Xu and Randall 1995; Tao at al. 1996; Liu and Moncrieff 1998; Sui et al. 1997) and general circulation models (e.g., Randall et al. 1991; Lieberman et al. 1994; Lin et al. 2000) have been useful to attempt to diagnose the aforementioned causes of the diurnal cycle of convection over the Tropics. While these models allow a unique test bed to examine the physics of the diurnal cycle of precipitation, errors in model physics (e.g., radiation, microphysics, or convective parameterizations) may lead to inappropriate conclusions about the true causes of the diurnal variation (Randall et al. 1991; Lin et al. 2000; Yang and Slingo 2001). Due to the subtle differences in numerical model simulations and observational datasets both in situ and remotely sensed, the question as to which of these mechanisms dominates the physics behind the diurnal cycle in a particular location or meteorological regime remains an open one.

The launch of the Tropical Rainfall Measuring Mission (TRMM) satellite in November 1997 allows data from the first quantitative spaceborne rain radar, the precipitation radar (PR), to be combined with data from the non-sun-synchronous TRMM microwave imager (TMI). The TRMM platform provides the first threedimensional snapshots of the radar reflectivity field and coincident passive microwave brightness temperatures of precipitating systems' structures from space. While also measuring a remote sensing proxy for rainfall-like measurements made from IR and microwave radiometers, the TRMM PR's 2A25 reflectivity-rain-rate algorithm can provide a more physically direct measurement of near-surface rainfall than other remote sensing proxies like IR cloud-top temperatures (which may or may not be related to surface rainfall) and low-frequency microwave brightness temperatures (which are available only over ocean and are proportional to the optical depth of the rain layer). Convective intensity can also be inferred from the radar reflectivity profiles and $85-\mathrm{GHz}$ microwave ice scattering signatures provided by TRMM.

Despite the benefit of high spatial resolution $(4.3 \mathrm{~km}$ $\times 4.3 \mathrm{~km}$ at the satellite's nadir point), temporal sampling is reduced when compared to IR satellite measurements or hourly surface reports. Since each overpass of a given location by the PR's narrow $(215 \mathrm{~km})$ swath occurs infrequently $\left(\sim 0.5-2\right.$ times day $\left.^{-1}\right)$, longtime composites of rainfall estimates must be constructed 
from the TRMM estimates in order to reconstruct the diurnal cycle of rainfall with sufficient sampling. However, once these composites are created, they may be used to infer the diurnal cycle of radar-estimated rainfall and convective intensity consistently and quantitatively Tropicswide. The precipitation feature (PF) algorithm described in Nesbitt et al. (2000) is applied to obtain these parameters for differing types of PFs ranging from small systems to large MCSs, allowing a Tropicswide quantification of the observed diurnal cycle of rainfall and convective intensity by rainfall system type.

\section{Data and methods}

\section{a. The TRMM satellite}

This study uses data from the TRMM satellite's PR and TMI, extending temporally from December 1997 to November 2000. Kummerow et al. (1998, 2000) detail the specifications of the PR and TMI instruments aboard the TRMM satellite employed in this study. Briefly, the PR is a three-dimensional spaceborne precipitation radar that, at its nadir point, has $4.3 \mathrm{~km} \times 4.3$ $\mathrm{km}$ horizontal resolution and a vertical resolution of 250 m. ${ }^{1}$ The PR retrieves reflectivities at a frequency of 13.8 $\mathrm{GHz}$ from the surface to $20 \mathrm{~km}$ above the earth ellipsoid. It has a $215-\mathrm{km}$ swath width with a minimum detectable signal of nearly $17 \mathrm{dBZ}$ (which limits the sensitivity of its rain estimates to about $\left.0.5 \mathrm{~mm} \mathrm{~h}^{-1}\right)$. This study uses the algorithm 2A25 and 2A23 (version 5; complete specifications of the TRMM datasets can be found online at http://tsdis02.nascom.nasa.gov/tsdis/Documents/ ICSVol4.pdf) attenuation-corrected reflectivity profiles and derived near-surface rain products [readers are referred to Iguchi et al. (2000) for details on the 2A25 reflectivity-rain rate algorithm]. Absolute errors in a given PR 2A25 near-surface rainfall estimate may be introduced due to uncertainties in the attenuation correction, drop size distribution, and nonuniform beamfilling assumptions. However, it is unlikely that these errors are large, or would significantly affect our results portraying the relative phase and amplitude of the diurnal cycle.

The TMI is a 9-channel, 5-frequency, elliptically scanning passive microwave radiometer. It has a viewing angle of $53^{\circ}$ off nadir, a 760-km swath width, and horizontal resolution of $5 \mathrm{~km} \times 7 \mathrm{~km}$ at $85 \mathrm{GHz}$ (resolution is constant across the entire swath). Polarizationcorrected temperatures (PCTs; Spencer et al. 1989) have been calculated at $85 \mathrm{GHz}$ to remove effects of surface emissivity variations over ocean and land surfaces:

$$
\mathrm{PCT}=\frac{\beta T_{b_{\mathrm{H}}}-T_{b_{\mathrm{V}}}}{\beta-1} .
$$

The horizontally and vertically polarized channels are

\footnotetext{
${ }^{1}$ Instrument specifications corresponded to the pre-TRMM altitude boost, which occurred in Aug 2001.
}

used ( $T_{b_{\mathrm{H}}}$ and $T_{b_{\mathrm{V}}}$, respectively) to calculate 85 PCT; the value for $\beta$ is 0.45 at $85 \mathrm{GHz}$ (Spencer et al. 1989). While PCTs in this frequency range may be warmed by as much as $10 \mathrm{~K}$ by emission from supercooled cloud liquid water (Toracinta et al. 2002), they are a good indication of the scattering optical depth of precipitation-sized ice particles within a cloud system, and the ability of the attendant convection to produce such ice particles. As with the PR products, the version 5 TMI products (algorithm 1B11) are employed in this study.

\section{b. The PF algorithm}

The PF algorithm defined in Nesbitt et al. (2000) is used to identify individual storms within the combined TRMM dataset. The PR and TMI data are collocated within the $215-\mathrm{km}$-wide PR swath to identify contiguous areas of PR rainfall and TMI $85-\mathrm{GHz}$ ice scattering. A nearest-neighbor matching technique was used to match the two datasets, meaning that every PR pixel was matched with the nearest TMI pixel, with the PR used as the base grid. The PF areas were required to be at least four PR pixels in size $\left(\sim 75 \mathrm{~km}^{2}\right)$ and to contain either PR near-surface reflectivities $\geq 20 \mathrm{dBZ}$ or 85 $\mathrm{GHz}$ PCT $\leq 250 \mathrm{~K}$. The PFs were then classified by their radar and ice scattering properties into three categories:

- PF without ice scattering (no pixels containing PCT $\leq 250 \mathrm{~K}$ at $85 \mathrm{GHz}$ ), likely "warm rain" features too shallow or those too small to contain significant ice scattering at TMI resolution;

- $P F$ with ice scattering (at least one pixel with $85-\mathrm{GHz}$ $\mathrm{PCT} \leq 250 \mathrm{~K}$ ), features with significant optical depths of ice aloft, but are not large or intense enough to meet the MCS category;

- PF with an MCS (PF contained at least $2000 \mathrm{~km}^{2}$ of contiguous area with $85-\mathrm{GHz} \mathrm{PCT} \leq 250 \mathrm{~K}$ and 185 $\mathrm{km}^{2} \leq 225 \mathrm{~K}$ ), defined to ensure a large convective system analogous to the Mohr and Zipser (1996) and Houze (1993) ice scattering and radar MCS definitions, respectively.

Figure 1 shows a schematic of these three types of features showing idealized PR radar reflectivity and TMI $85-\mathrm{GHz}$ brightness temperatures. Maintaining that PFs are at least four pixels in size containing near-surface reflectivities $\geq 20 \mathrm{dBZ}$ means that about $19 \%$ of the total raining pixels are not accounted for (between the PR minimum detectable signal of 17 and $20 \mathrm{dBZ}$ and PF size between one and four pixels); however, only about $4 \%$ of the total $2 \mathrm{~A} 25$ near-surface rainfall is missed.

Composites of the diurnal cycle are created by converting the time of observation (in UTC time) of a particular PF to local time based on its longitude. The PF's characteristics at the pixel level (type of PF, rainfall, PR profiles, and TMI brightness temperatures) are then binned in the appropriate local time bin. The location 

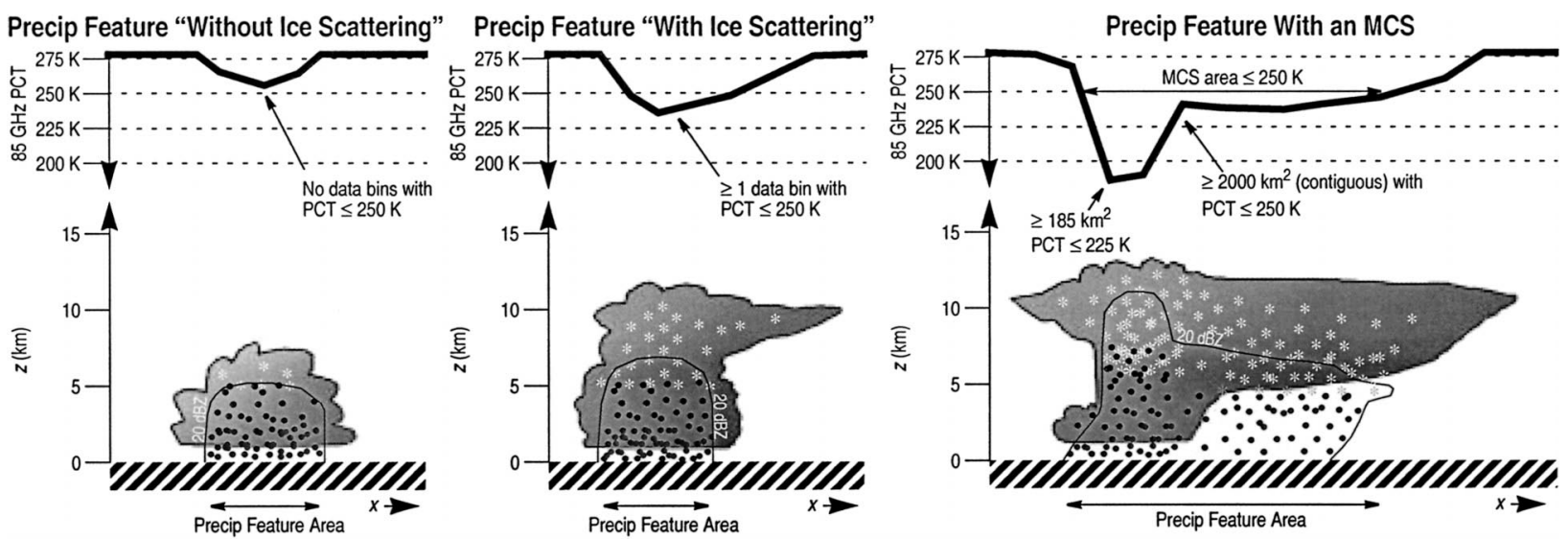

FIG. 1. Vertical cross-section schematic of the three PF types (from Nesbitt et al. 2000). Above each example cloud, composed of liquid and frozen hydrometeors (indicated by dots and asterisks, respectively), lies the idealized $85-\mathrm{GHz}$ PCT trace associated with the feature below. The schematic location of the $20-\mathrm{dBZ}$ contour is labeled.

of each PF is determined by its centroid location (using the technique of Mohr and Zipser 1996). Note that the land-ocean mask used in this study comes from the 2 A25 "method flag" (with a native 1-km resolution); each PF is assigned a land or ocean value based on the majority of pixels in each PF being over land or ocean (with features with equal numbers of land and ocean pixels going to land). Land versus ocean composites in sections 4 and 5, and the regional analyses in sections $6 \mathrm{~b}$ and $6 \mathrm{c}$ use this high-resolution land-ocean mask in their creation. Composites for the $10^{\circ} \times 10^{\circ}$ boxes described in section $6 \mathrm{a}$ use the centroid position of the PF to determine which grid box the PF is assigned to.

\section{c. Sampling issues}

The TRMM satellite orbits with an inclination of roughly $35^{\circ}$, providing data between approximately $\pm 36^{\circ}$ latitude. However, the narrow swath of the PR data $(215 \mathrm{~km})$ leads to geographic undersampling on a daily basis. The orbital pattern of the satellite allows sampling between 0.5 times day $^{-1}$ at the equator to nearly 2 times day $^{-1}$ at $35^{\circ}$ latitude. In addition, it takes

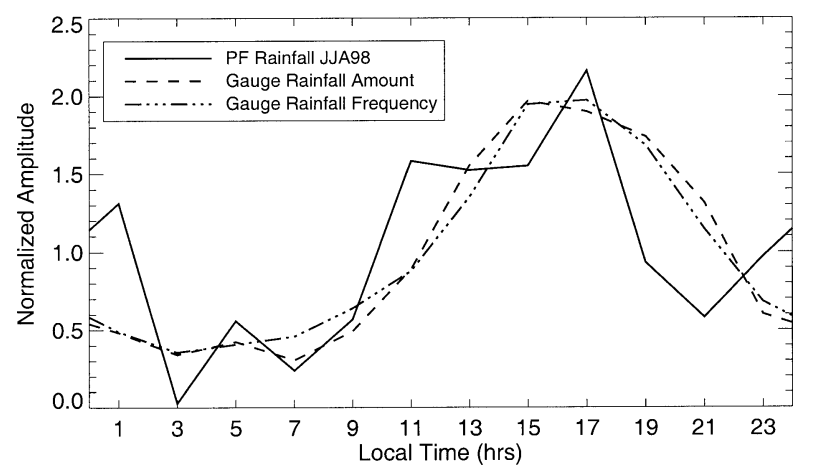

FIG. 2. The diurnal cycle of TRMM PF rainfall (solid), CDC gauge rainfall (dash), and rain frequency (dash-dot) over the southeast United States, normalized to the daily mean amplitude. about 46 days for the TRMM satellite to return to a given position at a given local time. Therefore, in order to sample the complete diurnal cycle at a particular location, it is necessary to composite a time span of data to allow the statistics of nonlinear fields like rainfall to converge at a particular location. Lin et al. (2000) found that at least 3 months of PR data must be combined to adequately sample a $4^{\circ} \times 5^{\circ}$ grid at 1 -h resolution. To test the statistical robustness of our method at its minimum confidence level, we have compiled three months of the National Oceanic and Atmospheric Administration Climate Prediction Center (NOAA CPC) hourly rain gauge data (Higgins et al. 1996) over the southeast United States $\left[2.5^{\circ}\right.$ longitude $\times 2^{\circ}$ latitude grids over land, east of $90^{\circ} \mathrm{W}$ and south of $35^{\circ} \mathrm{N}$ over land, similar to the analysis of Dai et al. (1999)] during June, July, and August $1998 .^{2}$ Figure 2 shows the diurnal cycle (in 2-h bins) of normalized rainfall amount from TRMM PFs over the same area and time period (solid line). Also plotted is the coincident NOAA CPC normalized rainfall amount and frequency (hours with greater than $0.1 \mathrm{~mm} \mathrm{~h}^{-1}$ rain accumulation). Normalized is defined as dividing the bin totals by the daily mean value. The TRMM rainfall data generally follow the trend of the gauge data for both phase and amplitude given the constraints of sampling mentioned above. Aware of this sampling constraint, in this paper we examine the diurnal cycle from relatively large areal composites of TRMM data combined into a 3-yr composite (December 1997-November 2000) with no less than 2-h bin temporal resolution and $10^{\circ} \times 10^{\circ}$ spatial resolution. Because of these sampling issues, investigation of the diurnal cycle on smaller geographic $\left(<10^{\circ} \times 10^{\circ}\right.$ grids $)$ and temporal scales (i.e., seasonal) will await the accumulation of more data. For a comprehensive seasonal

\footnotetext{
${ }^{2}$ Quality-controlled hourly gridded rainfall data over the United States are available only through calendar year 1998 at the time of submission.
} 

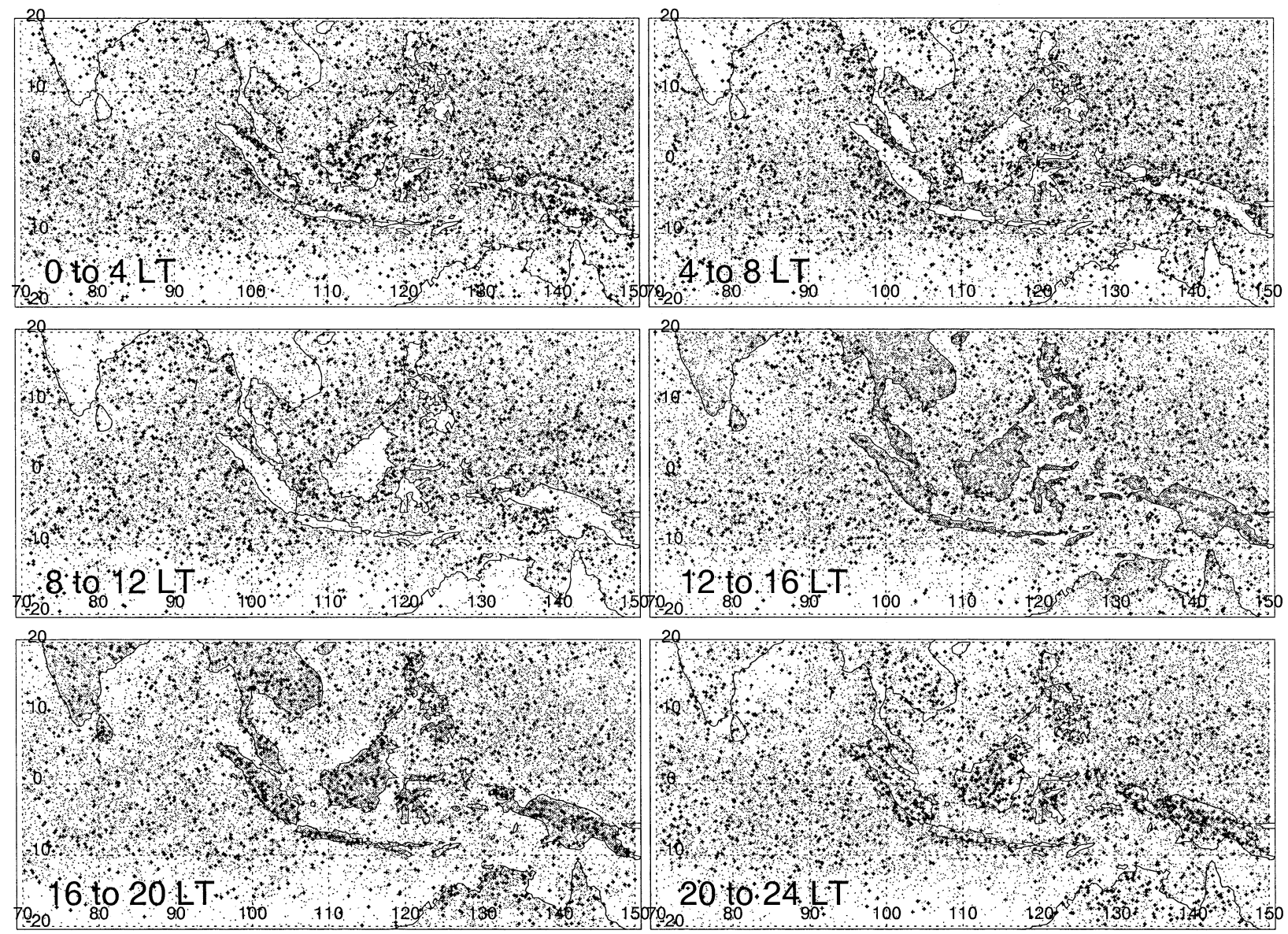

FIG. 3. The locations of PFs with ice scattering (dots) and MCSs (small crosses) in the Maritime Continent region. Each of the six panels displays a 4-h time bin (LT).

analysis of the diurnal cycle of precipitation frequency from surface weather reports, the reader is referred to Dai (2001).

Variability of rainfall also occurs on longer timescales other than diurnally. Nondiurnal rainfall enhancements from passing easterly wave disturbances, midlatitude shortwave troughs, and other phenomena like the Madden-Julian oscillation are aliased in our long-term averages. No attempts to remove these variations caused by these phenomena are made in our results, nor are the phenomena believed to significantly alter our conclusions.

\section{Examples of diurnal variability from TRMM}

The Maritime Continent region in Southeast Asia represents a unique geographic region that contains large islands, narrow peninsulas, and complex terrain surrounded by large oceanic and continental areas. As a result, effects applicable both to the large-scale and local effects drive the diurnal cycle of PFs (cf. Williams and Houze 1987; Oki and Musiake 1994). Figure 3 is a plot of the diurnal variability of three years (all seasons) of sampled PFs with ice scattering (gray dots) and PFs with MCSs (black crosses) in the Maritime Continent region split into 4-h time bins for each panel of the plot. During the late morning hours [0800-1200 local time (LT)], the land areas are largely devoid of PFs relative to the surrounding ocean regions. Four hours later (1200-1600 LT), many PFs with ice scattering appear over the islands and continental regions, with enhancements along the coasts (associated with sea-breeze effects) and mountain ranges (especially along the higher terrain in New Guinea). Progressing to 1600-2000 LT, these features continue to be focused over land areas, with PFs with MCSs appearing likely because of upscale growth from smaller features earlier. Also, note the suppression of features just offshore resulting from subsidence from sea-breeze circulations. Later (2000-0000 and 0000-0400 LT), the ratio of PFs with MCSs to those with ice scattering is increased over land due to the loss of daytime convective instability and increased convective organization there. By 0400-0800 LT, the number of features over land is returning to the levels in the first panel discussed. Note that throughout the day, there are much smaller diurnal cycle variations over 
(a.)

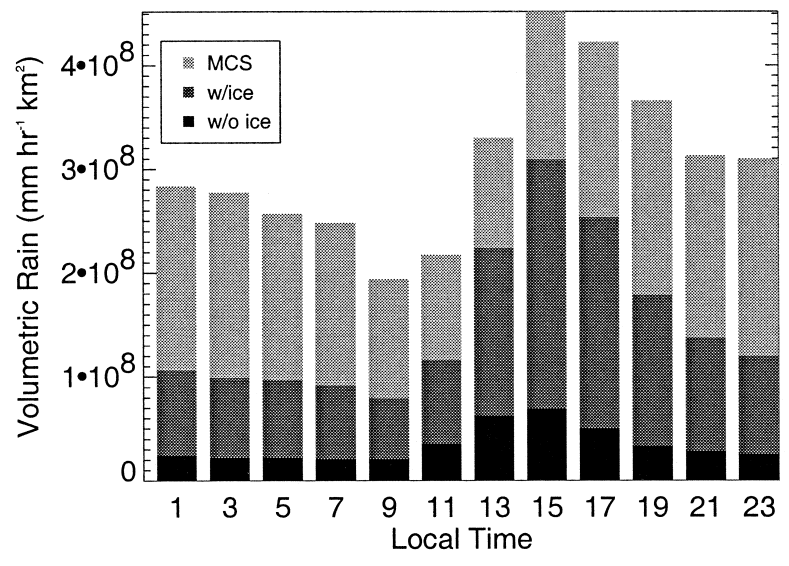

(c.)

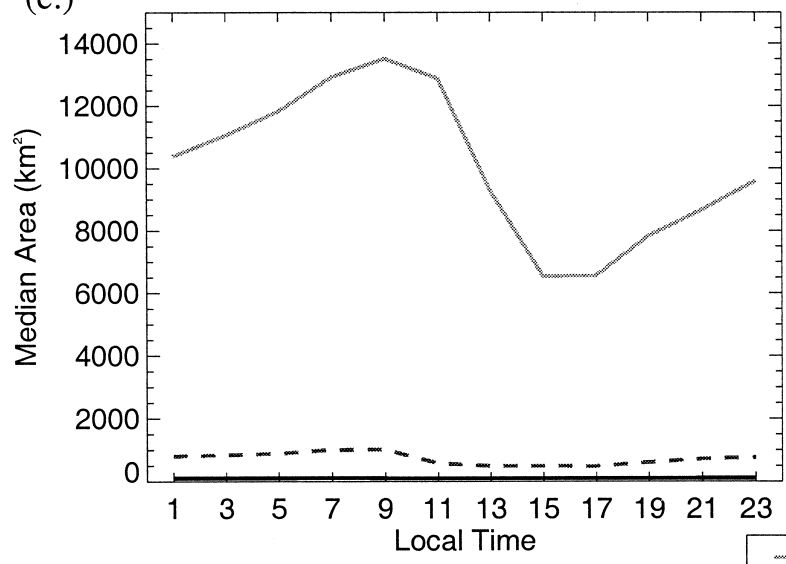

(b.)
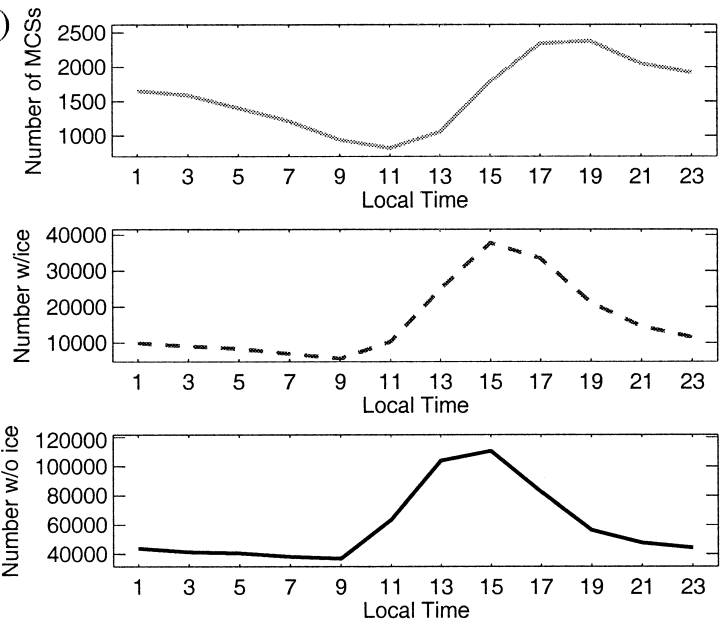

(d.)

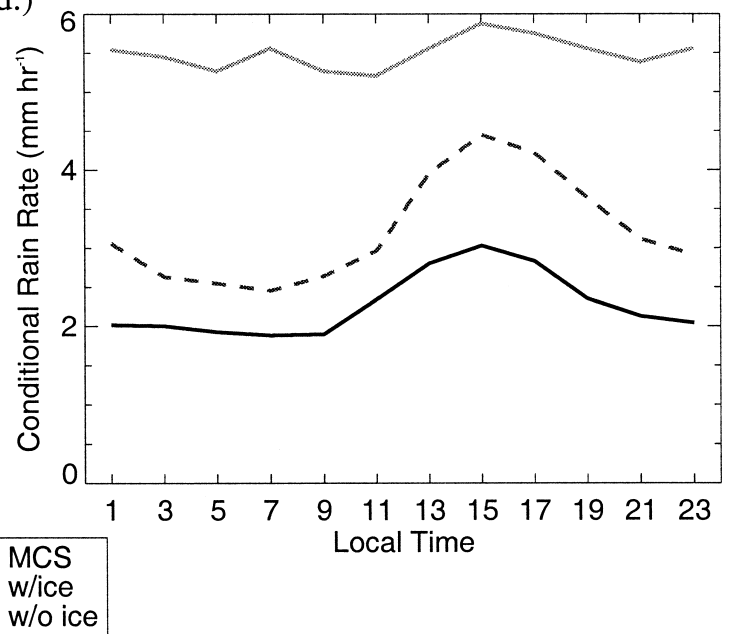

FIG. 4. Diurnal rainfall and other characteristics of PFs in the database over land within $\pm 36^{\circ}$ lat. The shading of the bars or line style represents the feature type indicated in the legend. The following characteristics of the diurnal properties of the rainfall budget by $\mathrm{PF}$ type are displayed: (a) total volumetric rainfall, (b) total number of features observed, (c) median area, and (d) mean conditional rain rate.

isolated ocean areas than over land areas. As shown below, this small diurnal variation in the number of features controls a similarly small diurnal variation in oceanic rainfall.

\section{Land and ocean differences in the diurnal cycle \\ a. The diurnal rainfall budget}

This section seeks to describe the bulk characteristics of the Tropicswide diurnal cycle of rainfall from PFs. Figures 4 and 5 show several characteristics (broken into 2-h bins) of the diurnal cycle of PFs by type over land (Fig. 4) and ocean (Fig. 5) areas. Figures 4a and 5a plot the retrieved $2 \mathrm{~A} 25$ volumetric rainfall $\left(\mathrm{mm} \mathrm{h}^{-1}\right.$ $\mathrm{km}^{2}$ ) by feature type. Volumetric rainfall is a parameter defined by Mohr et al. (1999) that sums average rain rates for each $\mathrm{PF}$ in volume per unit time, rather than average depths per unit time. This statistic is used because instantaneous rain rates are scarcely unique across the spectrum of PFs. The shading of the bars indicates the type of feature plotted. Figures $4 \mathrm{~b}$ and $5 \mathrm{~b}$ plot the number of features by type in each graph. Figures $4 \mathrm{c}$ and $5 \mathrm{c}$ show the diurnal cycle of median area for each feature type; Figs. $4 \mathrm{~d}$ and $5 \mathrm{~d}$ indicate the mean conditional rain rate $\left(\mathrm{mm} \mathrm{h}^{-1}\right)$ for each type of feature (which is simply the mean rain rate within the raining area of each type of system).

All three types of PFs modulate the diurnal cycle of rainfall over land (Fig. 4a). There is a sharp early afternoon peak in overland rainfall [around 1500 LT, similar to the global results of Dai (2001)], enhanced by a peak in rainfall from PFs with and without ice scattering that both peak at this time. Non-MCS features yield a relative minimum of precipitation in the morning around 0900 LT, which also coincides with a diurnal minimum in the total rain. The distinct minimum around 0900 LT does not appear in the global analysis of Dai (2001); however, it does appear in several regional studies (e.g., 
(a.)

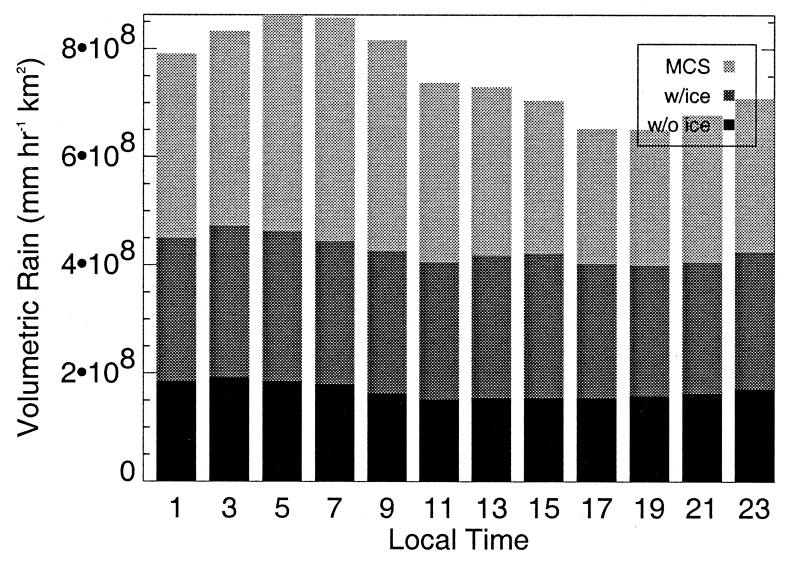

(c.)

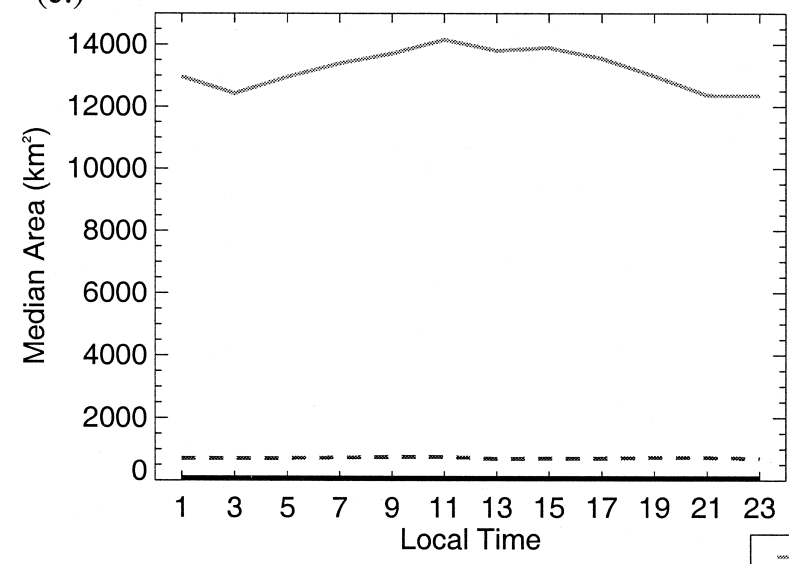

(b.)
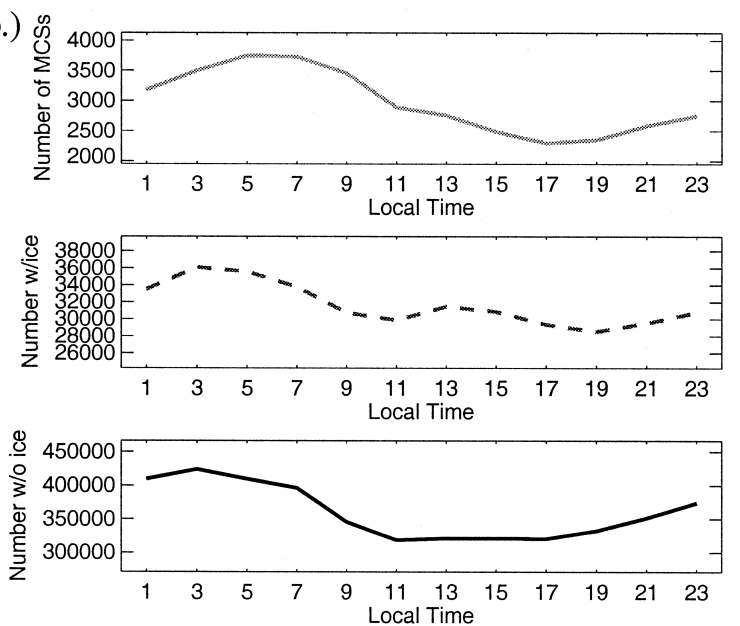

(d.)

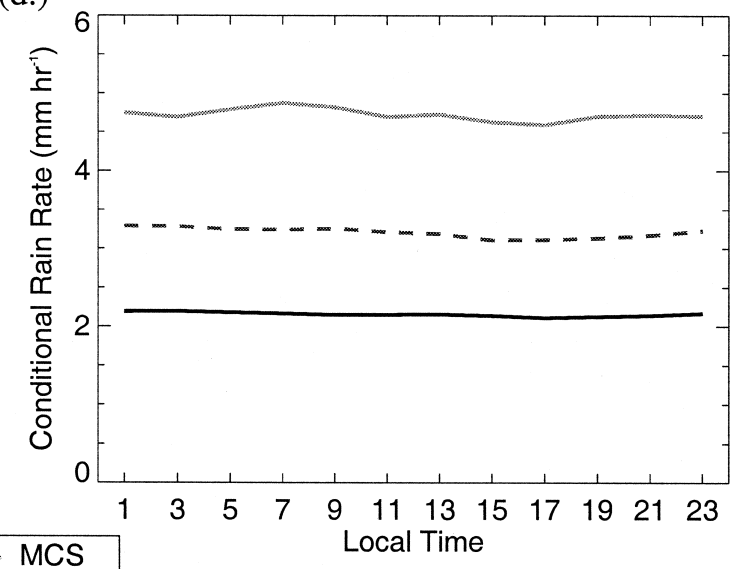

FIG. 5. As in Fig. 4, but for PFs over the ocean within the database.

the "inland" regime of Oki and Musiake 1994; Garreaud and Wallace 1997). Thus PFs with MCSs do not peak in rainfall contribution in the early afternoon: their peak occurs in a broad 6-h peak centered on 0100 LT. They yield a relative minimum of precipitation around noon LT.

To examine which factors control the diurnal cycle of rainfall, an analysis is performed of the contributing characteristics of the features by type. Total volumetric rainfall $\left(\Sigma R_{\mathrm{vol}}\right)$ can be expressed as the product of three parameters:

$$
\sum R_{\mathrm{vol}}=\overline{\mathrm{RR}_{\mathrm{cond}}} \bar{A} n \text {. }
$$

These parameters are mean conditional rain rate $\left(\overline{\mathrm{RR}_{\text {cond }}}\right)$, mean area $(\bar{A})$, and total number of features $(n)$. These parameters are plotted in the remaining three quadrants of Figs. 4 and 5 [except median area is plotted because of $\mathrm{PF}$ area's roughly lognormal distribution; see Nesbitt et al. (2000, their Fig. 5)].

Thus, PFs with and without ice scattering over land diurnally vary in number (Fig. 4b) and mean conditional rain rate (Fig. 4d) in a similar fashion as their total volumetric rainfall (all peaking in the early afternoon). This is offset somewhat by a lessening of median PF area in the early afternoon for these feature types (Fig. 4c). Thus, increased numbers of systems containing higher rain rates control the diurnal rainfall cycle for overland PFs with and without ice scattering. This finding is in contrast with the findings of Dai et al. (1999) using hourly rain gauge data, who find that over the southern United States, conditional rain rates remain more or less constant throughout the day. This is possibly due to differing geographic areas studied, but more likely due to the differing data types used in these studies. Heavy, short-lived, convective rain rates can be aliased in with lighter, longer duration rain events in hourly data, whereas instantaneous measurements (like those derived from the PR) can record these convective rain events.

In addition, PFs with MCSs have distinctly different factors contributing to their total volumetric rainfall. Mean conditional rain rates remain nearly constant 
throughout their daily cycle (Fig. 4d). The number of MCSs peaks in the evening (1700-1900 LT) as shown by Fig. 4b, slowly decreasing to a relative minimum in the late morning (around $1100 \mathrm{LT}$ ). In contrast, the median area (Fig. 4c) steadily increases from a minimum in the late afternoon (centered around $1600 \mathrm{LT}$ ) to a maximum around 0900 LT. Thus, the broad peak in overland MCS rainfall centered on 0100 LT (Fig. 4a) is contributed to by a balance of a decreasing number of systems that increase in area from evening to early morning. This result is similar to the overland mesoscale convective complex diurnal cycle found by Laing and Fritsch (1997).

The magnitude of the oceanic diurnal cycle of total rainfall (Fig. 5a) is considerably less than that over land areas, varying by a maximum-minimum ratio of 1.3:1 over oceanic areas versus a ratio of 2.25:1 over land areas. The total rainfall reaches a maximum near sunrise (nearly 0600 LT). Unlike land areas, all oceanic PF types peak in rainfall contribution in the early A.M. hours, with peaks at 0300, 0300, and 0700 LT for PFs without, with, and with MCSs, respectively. For features with and without ice scattering, the peak at $0300 \mathrm{LT}$ is only caused by a maximum in their count at that time (Fig. 5b); median area (Fig. 5c) and mean conditional rain rates (Fig. 5d) do not contain any appreciable diurnal cycle. A secondary peak in rainfall from features with ice scattering in the afternoon also corresponds to a peak in the number of features in the early afternoon. The later peak in MCS rainfall around 0700 LT (similar to the results of Mapes and Houze 1993) is contributed by a peak (near 0500 LT) and slow decrease in the number of systems (Fig. 5b), and a slow increase in MCS area around sunrise peaking near 1100 LT (Fig. 5c). Therefore, the diurnal cycle of rainfall over the ocean is almost completely due to an increase of the number of systems, not the rain rates contained in them. This is similar to the pattern derived from surface weather reports derived in Dai (2001). For oceanic MCSs, there is also a contribution from systems expanding in area through the early morning, delaying their rainfall maximum to 0700 LT, slightly later than the peak in the number of MCSs about $2 \mathrm{~h}$ earlier.

Mean conditional rain rates (Fig. 5d) for oceanic MCSs remain constant like their overland counterparts (Fig. 4d). Note that the oceanic mean conditional rainrate value of around $4.8 \mathrm{~mm} \mathrm{~h}^{-1}$ is significantly less than the mean value of nearly $5.7 \mathrm{~mm} \mathrm{~h}^{-1}$ over land.

\section{b. The diurnal cycle of convective and stratiform rainfall}

The PR algorithm 2A23 contains a rain type (i.e., convective-stratiform) classification (details of the 2A23 algorithm may be found online at http:// trmm.gsfc.nasa.gov/2a23.html); this is employed here to examine the diurnal variation in the structure of the PFs by type. While there is some ambiguity in applying any classification scheme of this type (see Biggerstaff and Listemaa 2000), convective and stratiform rain identification has important implications on net heating and divergence profiles within precipitating systems (Houze 1997), thus affecting estimates of their convective heat and moisture budgets.

Figures 6 and 7 show the diurnal cycle by system type of land and ocean rainfall identified as convective and stratiform "certain" and "probably" by the 2 A23 algorithm over land and ocean, respectively. The total diurnal cycle of stratiform rain over land (Fig. 6a) follows a pattern out of phase (having a broad peak at night) with the diurnal cycle of convective rain (Fig. $6 \mathrm{~b})$. This result agrees with the overland diurnal cycle of "nonshowery" and "showery" weather reports presented in Dai (2001). When breaking down the results by feature type over land, however, the diurnal cycle of stratiform and convective rain is different. For PFs with and without ice scattering over land (Figs. 6a,b), both stratiform and convective rainfall peak in the afternoon, with the diurnal cycle of convective rainfall having a larger relative variation from maximum to minimum. For MCSs over land, convective rainfall (Fig. 6b) increases to a nearly constant value between 1500 and 0100 LT, then slowly decreases throughout the early morning hours toward a relative minimum value at 0900 LT. Stratiform MCS rainfall (Fig. 6a) slowly increases through the afternoon and evening from a minimum around 1300 LT and remains nearly constant over night between 2300 and 0700 LT, with a sharp decrease just after local sunrise. Figure 6c shows that all three types of features peak in their fraction of rainfall convective in the afternoon. For features with and without ice scattering, this convective peak corresponds with a peak in total rainfall (Fig. 4a); MCS stratiform rainfall causes the peak in total rainfall to lag until after midnight (Fig. 4a). Over land, the mean conditional rain rates remain nearly constant in convective and stratiform pixels (Fig. $6 \mathrm{~d})$. With convective and stratiform conditional rain rates constant throughout the day, the afternoon increases in total conditional rain rate (Fig. 4d) is due to an increase in convective rainfall fraction (Fig. 6c), not an increase in the rain rates in convective or stratiform pixels.

Over the oceans, the partition of rainfall among stratiform and convective-identified areas is nearly equal (Figs. 7a,b). Both stratiform and convective rainfall peak with the total rainfall around 0500 to $0700 \mathrm{LT}$, consistent with the analysis of Dai (2001). The fraction of convective rainfall (Fig. 7c) remains nearly constant at just above $50 \%$ for all feature types throughout the diurnal cycle over the ocean.

Mean conditional rain rates remain constant for both convective and stratiform areas, for all feature types over both land and ocean (Figs. 6d and 7d). Total conditional rain rates over land increase (Fig. 4d) because the fraction of rain from convective pixels increases (Fig. 6c). From a convective-stratiform perspective over 
(a.)

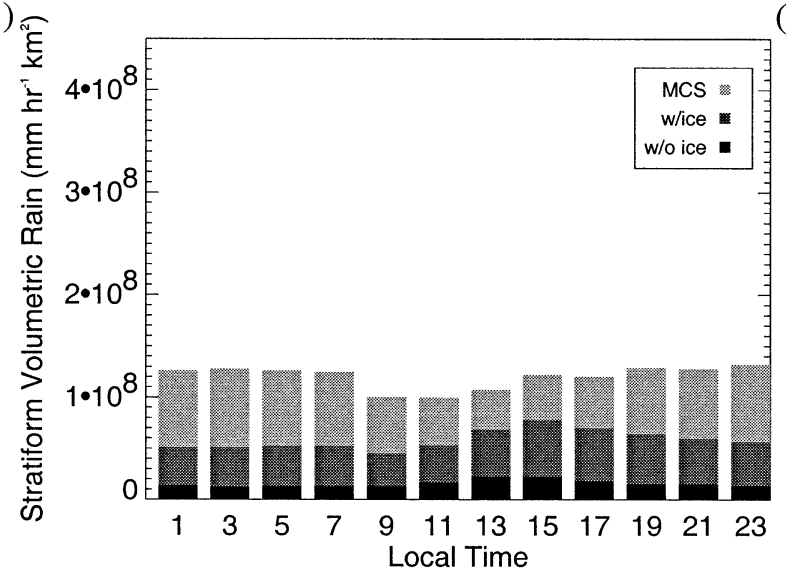

(c.)

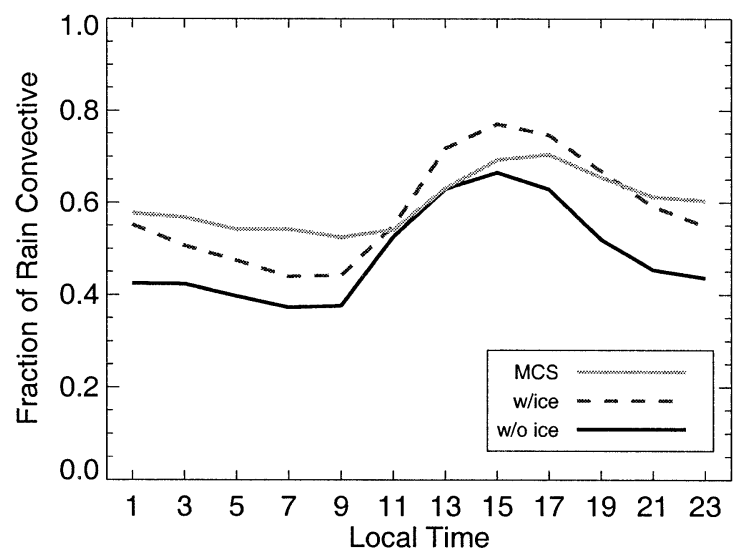

(b.)

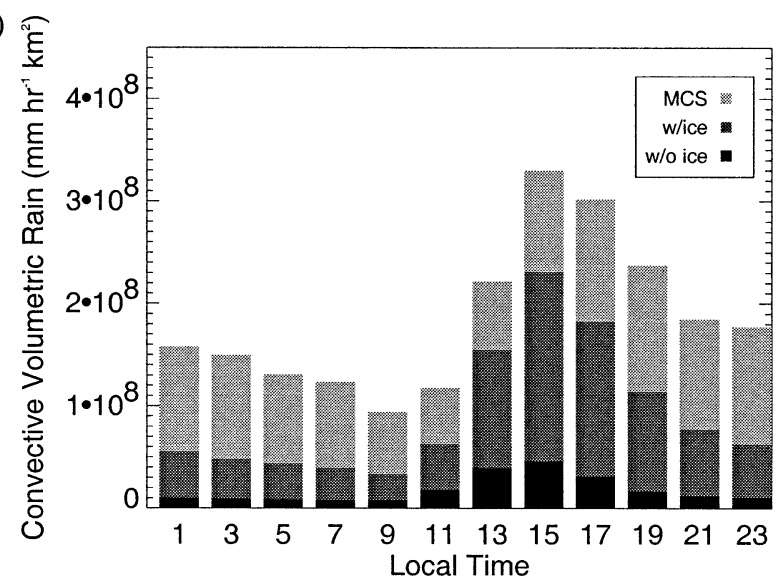

(d.)

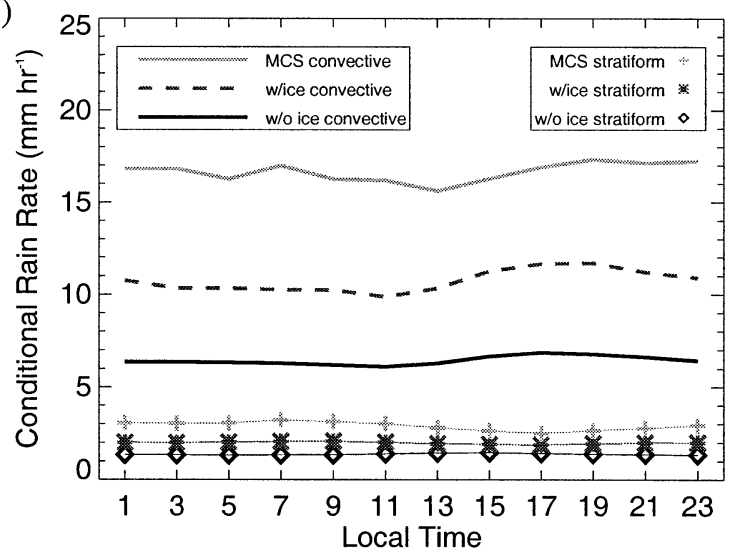

FIG. 6. Diurnal stratiform-convective characteristics of PFs in the database over land within $\pm 36^{\circ}$ lat. The shading of the bars or line style represents the feature type indicated in the legend. The following characteristics of the diurnal properties of the rainfall budget by PF type are displayed: (a) total stratiform volumetric rainfall, (b) total convective rainfall, (c) fraction of PF rainfall classified as convective, and (d) mean conditional rain rate in convective (thick lines) and stratiform (thin lines and symbols) pixels.

land, the increase in total rainfall in the afternoon is controlled by more systems that also contain a higher convective fraction [consistent with the destabilization hypothesis of Wallace (1975)], thus increasing rainfall. MCS convective rainfall is replaced by stratiform rainfall as the nighttime hours progress. This transition from heavier convective rain rates to lighter stratiform rainfall is offset by increasing median MCS area, these offsetting trends in the rainfall budget lead to a slow decrease in rainfall through the early morning.

Over the ocean, convective fractions (Fig. 7c) and mean conditional rain rates (both total and convectivestratiform) are constant. This relates that it is not raining harder during the nightime hours; the predawn rainfall maximum is caused by systems raining over a larger total area (caused by an increase in the number of systems). This leads us to clarify the current hypotheses, restricting them not to imply that the direct radiation or dynamics-radiation feedback mechanisms increase rainfall by increasing convective intensity or rain rates: they merely make the environment more favorable for the occurrence and bulk areal coverage of precipitating sys- tems at night. Nighttime conditions do not generate significantly heavier rain rates in this dataset.

\section{The diurnal cycle of TRMM-estimated convective intensity}

Several studies have used the TRMM satellite to examine proxies for convective intensity of precipitating systems in the Tropics (Nesbitt et al. 2000; Short and Nakamura 2000; Boccippio et al. 2000; Petersen and Rutledge 2001; Toracinta et al. 2002; Del Genio and Kovari 2002). The PF algorithm also allows examination of remote sensing storm peak intensity parameters that may be used to examine the convective diurnal cycle [see Nesbitt et al. (2000) for a more complete description of each]: minimum $85-\mathrm{GHz}$ PCT and maximum height of the 30-dBZ echo.

Brightness temperature depressions in the microwave regime rely on a complex interaction between ice hydrometeor phase and bulk density, particle size distribution, number concentration, and the total scattering depth of the ice layer (Vivekanandan et al. 1991). Ra- 
(a.)

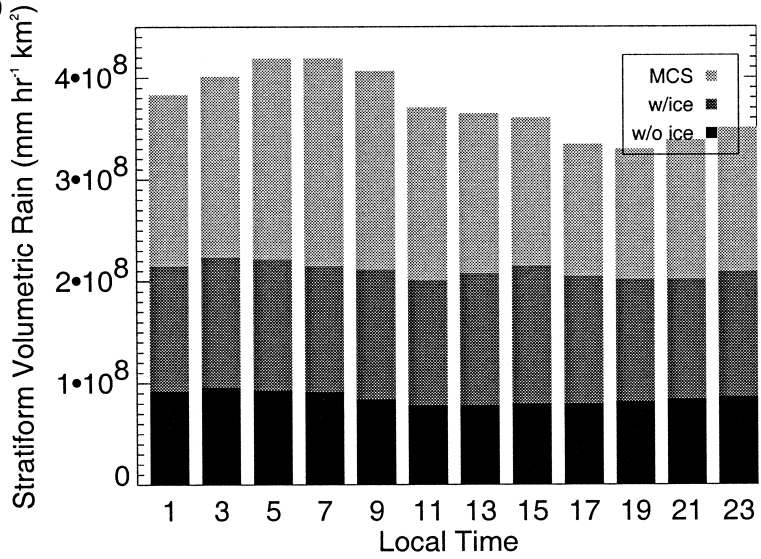

(c.)

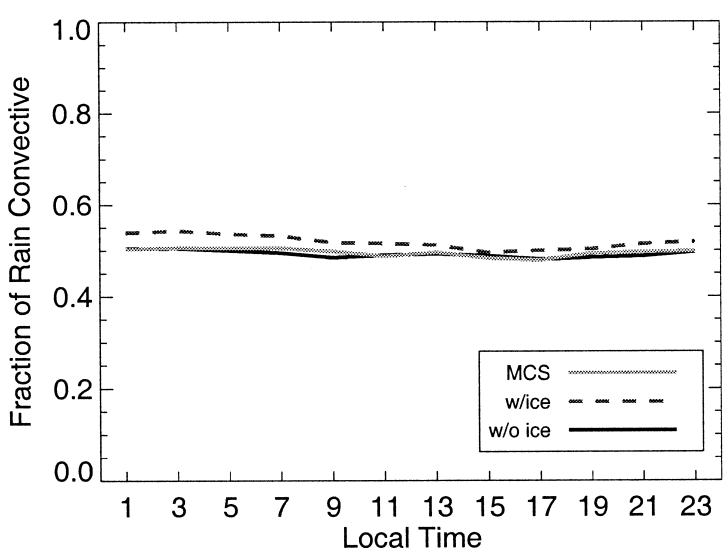

(b.)

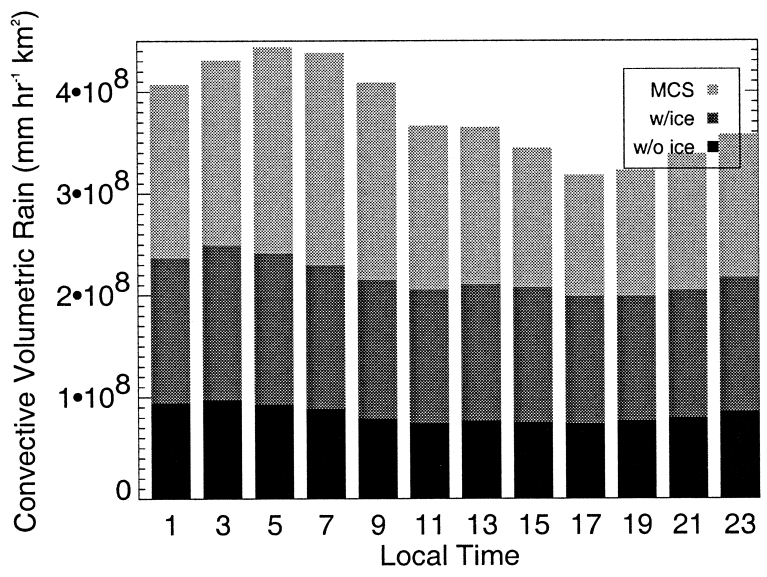

(d.)

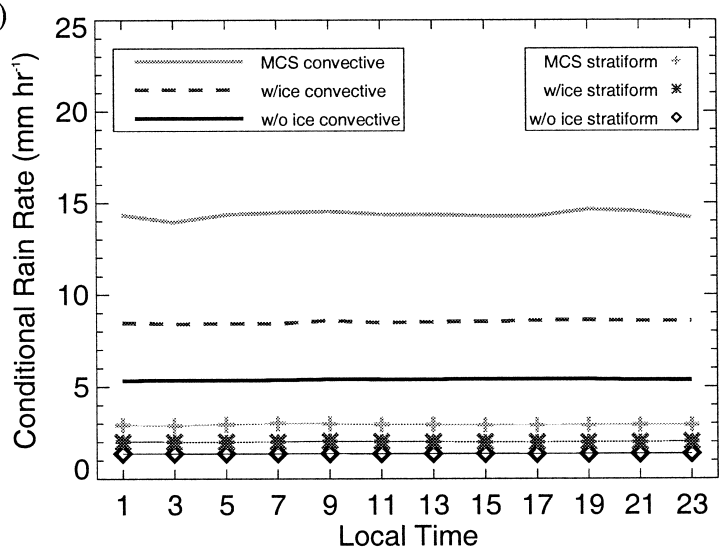

Fig. 7. As in Fig. 6, but for PFs over ocean within the database.

diative transfer calculations indicate that brightness temperature depressions at $85 \mathrm{GHz}$ are most sensitive to scattering by precipitation-sized ice particles greater than a few hundred micrometers in size. Here two indicators of maximum observed convective intensity within each system are presented (minimum $85-\mathrm{GHz}$ PCT, maximum 30-dBZ echo-top height). While these peak ice scattering and radar reflectivity parameters do not account for the areal coverage of intense pixels within each system (which may be correlated to bulk parameters, e.g., total latent heating), they do quantify an upper limit to the convective vigor that is possible in a given region (and are likely related with parameters such as maximum updraft strength and lightning probability). Evidence has associated these remote sensing proxies with peak convective intensity by many studies; the reader is referred to the introduction of Nesbitt et al. (2000) for a more complete discussion. Quantifying the diurnal cycle of convective intensity will provide an important validation of the diurnal variation of other observational parameters of precipitating systems like lightning (e.g., Petersen et al. 1996) that are highly related to measures of peak convective intensity.

Figures 8-10 show cumulative distribution functions
(CDFs) of PF intensity parameters for each type of feature over land and ocean; the contour levels for each intensity parameter indicate the percentile of intensity for the sample observed during that time bin. The data have been placed into 2-h bins. Extreme values in the database are plotted with the thick line.

Figure 8 shows the diurnal variation of the peak intensity parameters for PFs without ice scattering. Over the ocean (Figs. 8a,c), there is strikingly little diurnal variation in both measures of convective intensity. Over land (Figs. 8b,d), there is a notable mid- to late afternoon maximum in remotely-sensed convective intensity in the maximum heights of the 30 echo distribution. Brightness temperatures at $85 \mathrm{GHz}$ show slightly more intense ice scattering in the nighttime hours, likely indicating surface and beam-filling contamination from these weak, optically thin and/or small features mixed with background radiation.

The PFs with ice scattering convective intensity parameters are plotted in Fig. 9. Again, there is very little diurnal variation in the intensity parameters over the ocean (Figs. 9b,d). However, over land, a marked afternoon trough (ridge) in minimum $85-\mathrm{GHz}$ PCT (maximum 30-dBZ echo-top heights) are indicative of stron- 

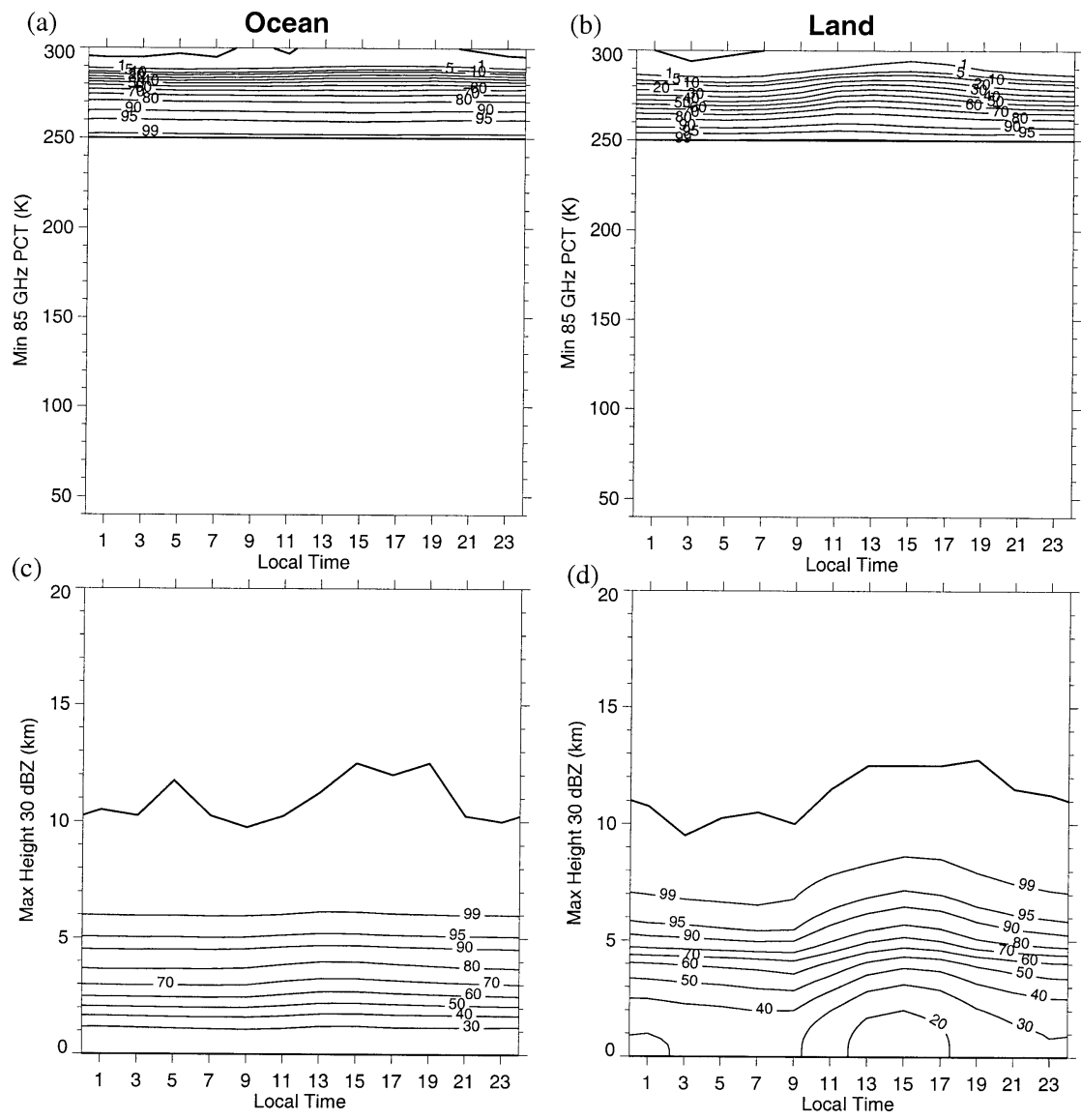

FIG. 8. The PF without ice scattering time-intensity CDFs of minimum 85-GHz PCT (a) over ocean and (b) over land; maximum height of the 30-dBZ echo (c) over ocean and (d) over land. Extreme values are denoted by the thick line.

ger convection during the afternoon. Overland ice scattering intensity at $85 \mathrm{GHz}$ peaks in intensity later (around $1700 \mathrm{LT}$ ) in general than radar reflectivity measures (around $1500 \mathrm{LT}$ ); this lag is likely indicative of upscale growth of the anvils of these systems. Strong, high-reflectivity updrafts (raising echo-top height distributions) create and subsequently loft large concentrations of precipitation-sized ice particles into the anvils (depressing ice scattering brightness temperatures). There also exists an apparent phase shift depending on intensity in each measure; for example, features in the 20th and 30th percentile of maximum 30-dBZ heights peak in intensity around 1500 LT, while features in the 80th and greater percentiles peak around 1700 LT. Around sunrise, all parameters over land in the roughly 80th percentiles and less assume values roughly equal to the median oceanic values, whereas during the period of daytime insolation they become increasingly intense.

Figure 10 presents the diurnal cycle of convective intensity from MCSs. Again, the convective intensity of MCSs over the ocean is quite steady throughout the day. From the minimum 85-GHz PCT (Fig. 10a) and maximum height of the 30-dBZ (Fig. 10c) echo distri- butions, it appears as though over the ocean there may be a slight preference for more intense ice scattering and radar reflectivity profiles in the early morning hours. Over land, convective intensity is again maximized in the midafternoon (Figs. 10b,d), due to the presence of more extensive and optically thick volumes of ice (graupel and hail) in MCSs at that time.

None of the measures of oceanic maximum convective intensity show an appreciable convective intensity diurnal cycle. This is corroborative evidence to show that peak convective processes (along with constant convective area fraction as mentioned above) are not invigorated over the ocean during the early morning rainfall maximum. The rainfall maximum is due to a larger number of systems, as discussed previously, not differing convective intensities or heavier rain rates within oceanic systems. Over land, afternoon convective processes are more intense and extensive (leading to decreased beam-filling effects); these effects along with increased convective rain fraction (and thus higher total conditional rain rates), and numbers of features increases rainfall in the afternoon, especially for sub-MCS fea- 

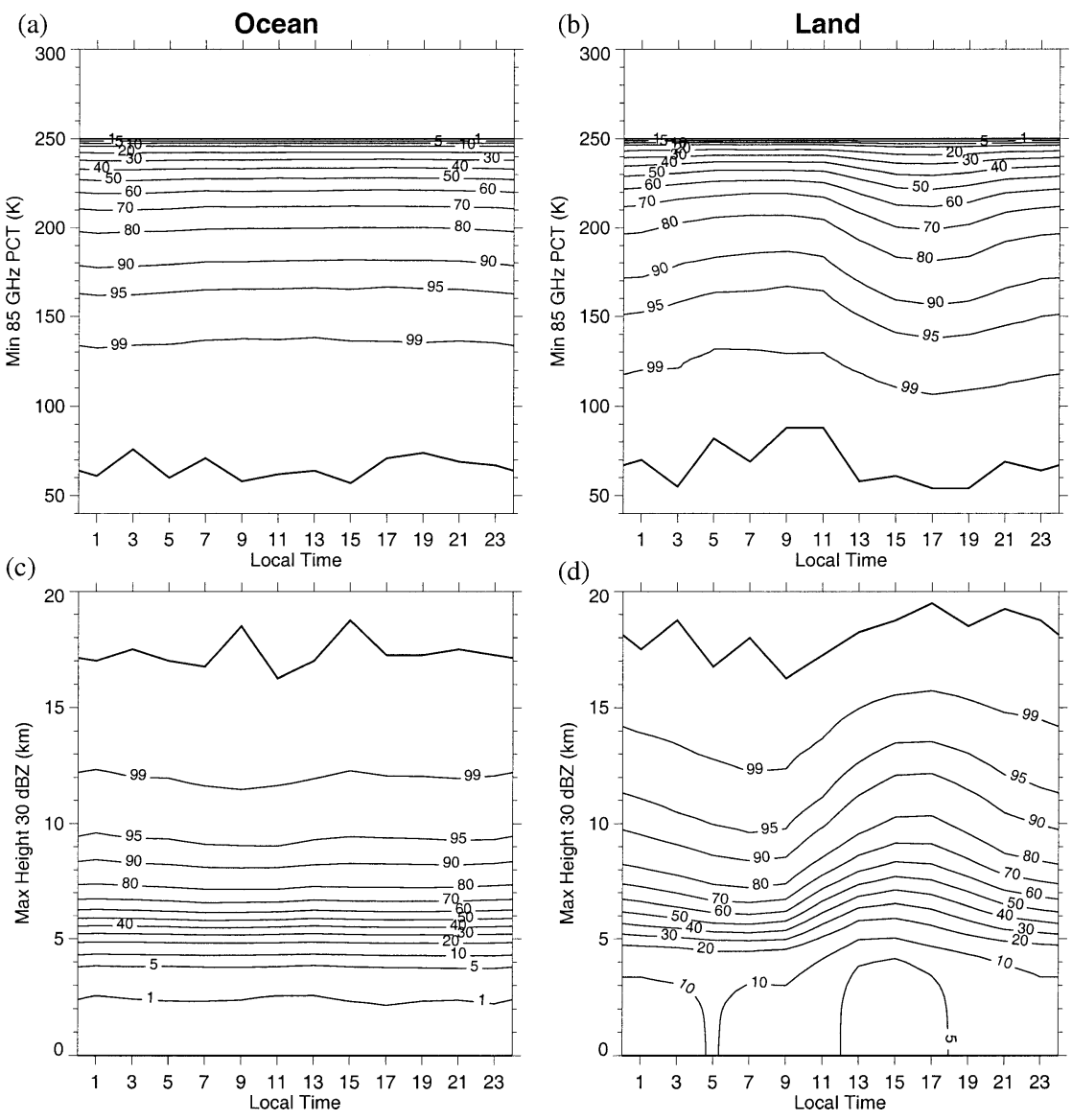

FIG. 9. The PF with ice scattering time-intensity CDFs of minimum $85-\mathrm{GHz}$ PCT (a) over ocean and (b) over land; maximum height of the 30-dBZ echo (c) over ocean and (d) over land. Extreme values are denoted by the thick line.

tures where convective rainfall dominates the diurnal cycle.

\section{Regional characterization of the PF diurnal cycle}

The characterization of the general properties and variation of the diurnal cycle of PFs on a regional basis is important in diagnosing regional precipitation and latent heating estimates from observations and numerical models, which have a direct link to our understanding of the general circulation (e.g., Hartmann et al. 1984). The PF database has been subsetted here to examine the regional variability of the diurnal cycle.

\section{a. Tropicswide phase and amplitude of the diurnal cycle}

Figure 11 shows the diurnal cycle of rainfall from PFs by type in $10^{\circ} \times 10^{\circ}$ grid boxes. The amplitude and phase (in local time) of the first Fourier component of rainfall are shown, with the amplitude defined as the ratio of the maximum of the Fourier fit to the mean daily volumetric rainfall in each box; phase is simply the time of the maximum of the Fourier fit. In Fig. 11a MCS rain areas with less than $2.5 \times 10^{6} \mathrm{~mm} \mathrm{~h}^{-1} \mathrm{~km}^{2}$ volumetric rainfall have been empirically screened due to insufficient numbers of MCSs in the given region. Over most open ocean boxes, the phase of the rainfall maximum is within a few hours of 0600 LT, especially in the deep Tropics. The subtropical oceans contain some exceptions, likely due to the forcing of MCSs being more synoptic in nature. A large fraction of continental boxes contain MCS maxima within a few hours of midnight, while many Northern Hemisphere subtropical land areas (like the United States and Asia) contain late afternoon maxima. The diurnal MCS rainfall amplitudes have similar values over land and ocean areas, with rainfall amplitudes between 1.5 and 2 times the mean. Phase differences between Fig. 11 (the diurnal cycle for all $3 \mathrm{yr}$ of data by PF type) and the total PF rainfall-gauge comparison in Fig. 2 over the southeast United States [encompassing June-August (JJA) in 1998 only] can be attributed to the limited sample in Fig. 2 compared with the 3-yr sample in Fig. 11, and the separation of the diurnal cycle of rainfall into the 

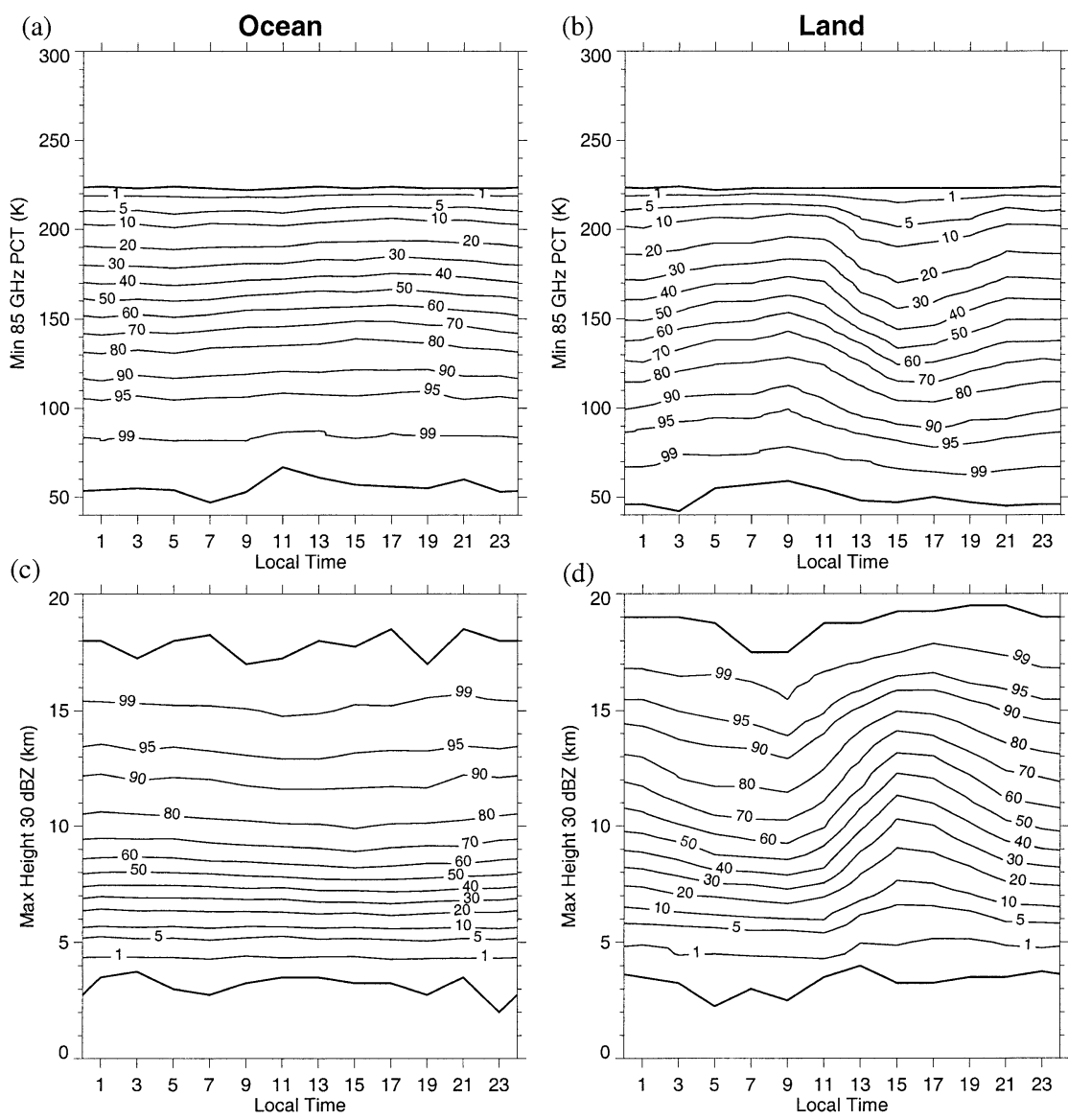

FIG. 10. The PF with MCS time-intensity CDFs of minimum 85-GHz PCT (a) over ocean and (b) over land; maximum height of the 30-dBZ echo (c) over ocean and (d) over land. Extreme values are denoted by the thick line.

three PF types in Fig. 11. The relative contribution of each PF type to the total rainfall diurnal cycle in each region (as in Fig. 11) determines the total rainfall diurnal cycle in that region.

The PFs with ice scattering over land have higher diurnal amplitudes than over ocean, and peak in rainfall in the mid- to late afternoon. The only exception over ocean is within the low-precipitation areas of the Southern Hemisphere subtropical highs, where the sample size is low. Over the ocean, the magnitudes of the rainfall diurnal cycle for PFs with ice scattering are relatively uniform, but the phases varies significantly. The majority of boxes contain maxima from midnight to early morning hours, with a notable exception being the North Pacific north of $35^{\circ} \mathrm{N}$ containing a peak in the evening. The PFs without ice scattering have a distinct oceanic maximum in the early morning hours; with the amplitude roughly inverse to the climatological precipitation values (see Fig. 12 for the TRMM 3B43 precipitation during the same period). Over land, the magnitudes are consistently greater than those over high precipitation areas of the ocean, with a consistent peak around 2 times the mean timed in the early to midafternoon. While the results in Fig. 11 are roughly consistent with the bulk all-land and all-ocean values discussed previously, important regional variations exist, which are a function of both bulk and local forcings (as shown in Fig. 3 over the Maritime Continent).

\section{b. Regional rainfall diurnal cycles}

In order to expand on the results in the previous section, this section groups PFs observed in regions that likely contain similar climate forcings and thus, in bulk, similar forcings for the precipitating systems diurnal cycle. The regions used in this analysis appear in Fig. 12; the mean (December 1997-November 2000) $1^{\circ} \times$ $1^{\circ}$ daily rainfall from the TRMM-combined 3B43 algorithm is shaded for reference (see Adler et al. 2000 for more details). Note in the figure that some regions contain overland or ocean areas only, while some are mixed land and ocean regions.

Figure 13 shows the diurnal cycle of total volumetric rainfall by region and PF type, plotted in polar coordinates and normalized to the daily mean rainfall for that feature type and region. The data are again binned 

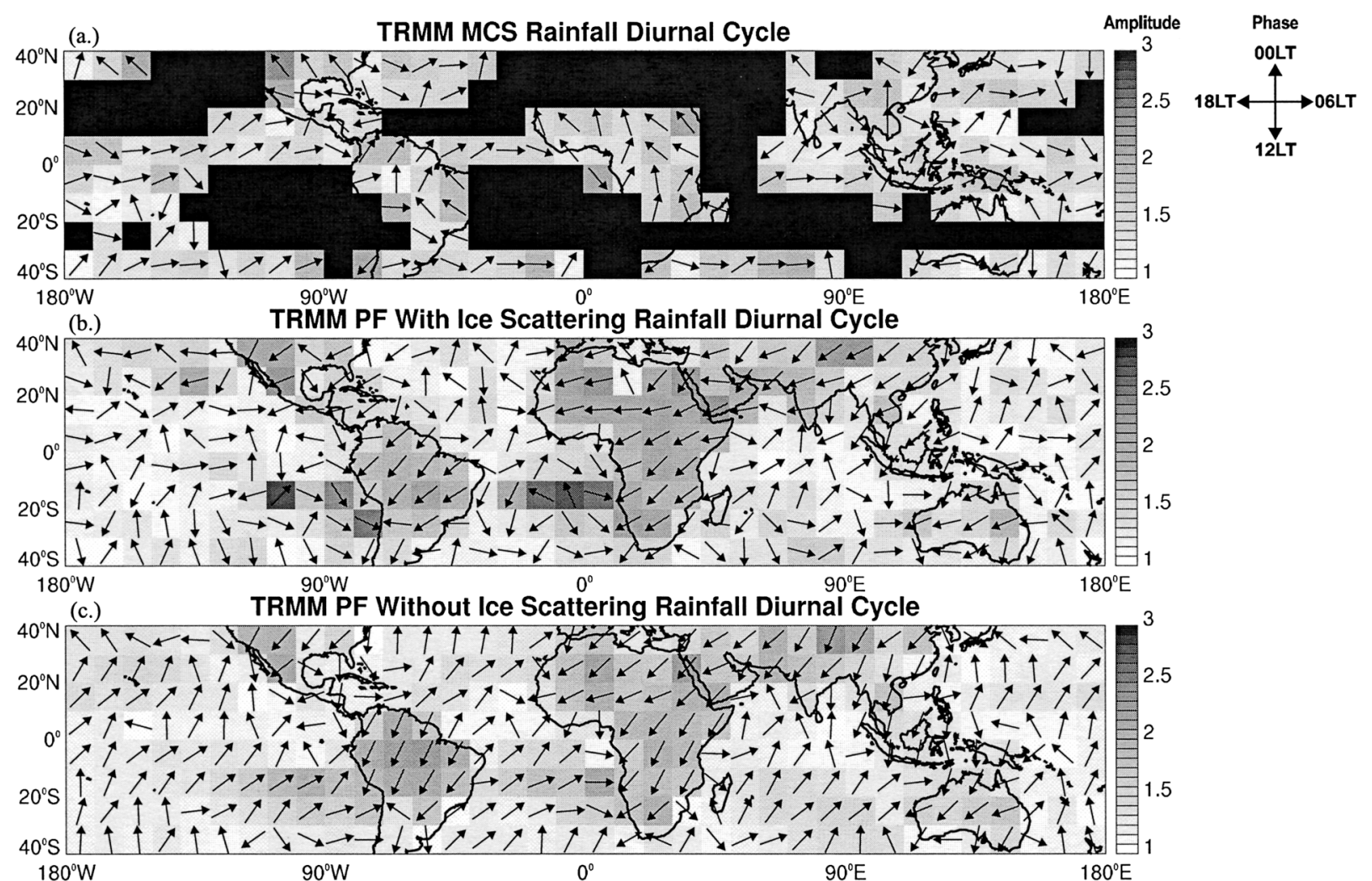

FIG. 11. The diurnal cycle of rainfall amplitude (shading) and phase in hours of LT (arrows) from PFs by type: (a) PFs with MCSs, (b) PFs with ice scattering, (c) PFs without ice scattering. Amplitude and phase are defined as the percentage variation and time of maximum in the first Fourier component of the rainfall within each $10^{\circ} \times 10^{\circ}$ box, respectively. MCS grid boxes in (a) containing less than $2.5 \times$ $10^{6} \mathrm{~mm} \mathrm{~h}^{-1} \mathrm{~km}^{2}$ volumetric rain have been screened due to insufficient sampling.

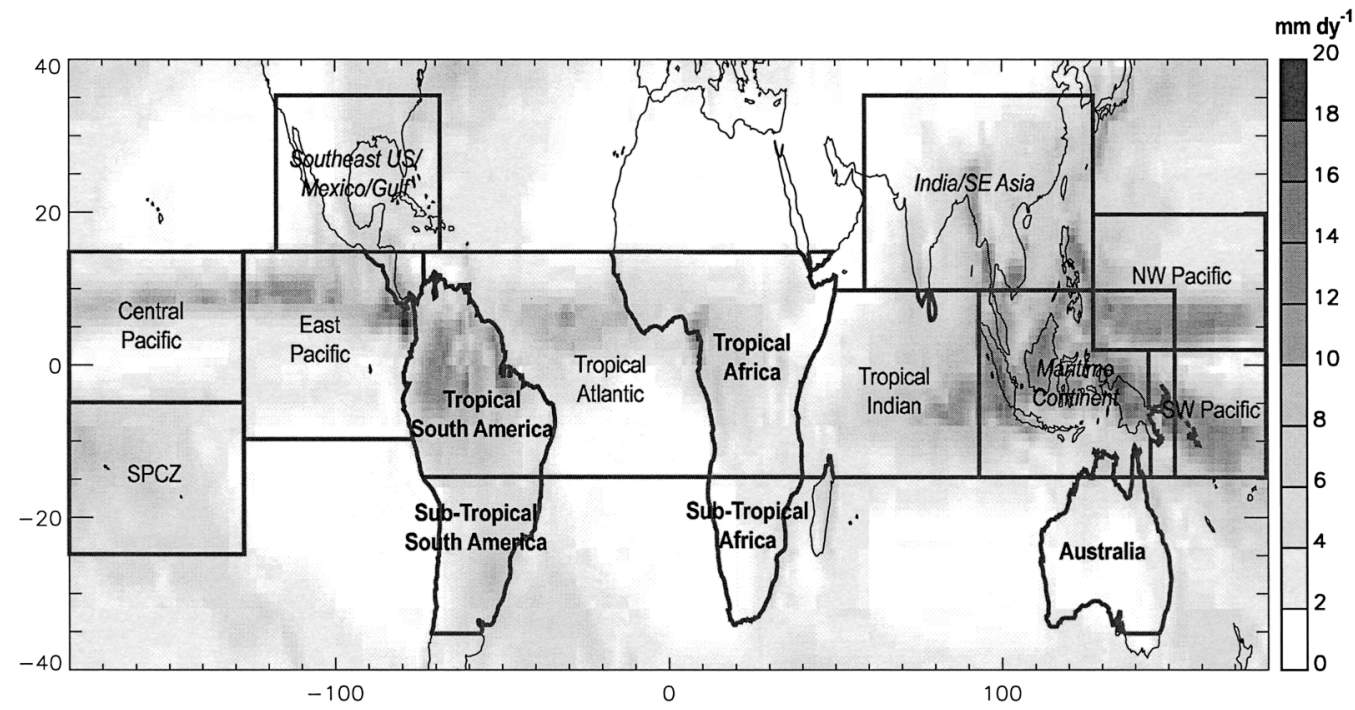

FIG. 12. Regional boundaries used in this study. Regions in plain type include only ocean areas, regions in boldface type include only land areas, while regions in italics include both land and ocean areas. The shading indicates the mean daily precipitation $\left(\mathrm{mm} \mathrm{day}^{-1}\right)$ from the TRMM 3B43 combined precipitation algorithm (Adler et al. 2000). 

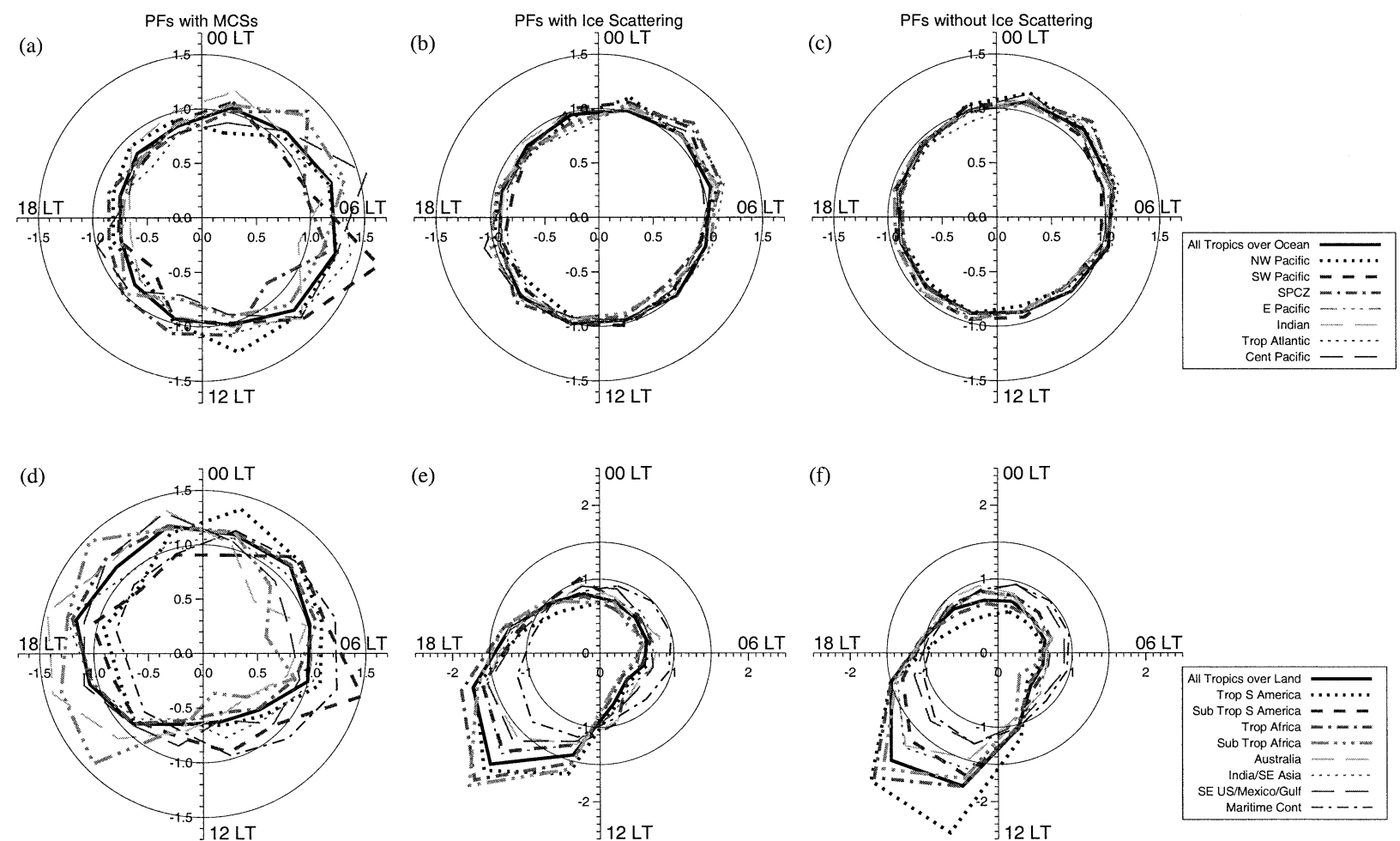

FIG. 13. The diurnal cycle of of regional rainfall, with amplitude normalized to the regional mean value, plotted by PFs type: (a) PFs with MCSs over ocean, (b) PFs with ice scattering over ocean, (c) PFs without ice scattering over ocean, (d) PFs with MCSs over land, (e) PFs with ice scattering over land, and (f) PFs without ice scattering over land. The legends at the right correspond to the row of figures to their left. Note the larger ranges on (e) and (f). The thin circles indicate amplitudes of 1.0 and 1.5 times the mean.

into 2-h blocks. Ocean regions are plotted in Figs. 13a$\mathrm{c}$; and land and mixed land and ocean regions are shown in Figs. 13d-f. In each figure, the global mean ocean and land amplitudes are plotted (thick line) in the corresponding figures.

For features with and without ice scattering over the ocean (Figs. 13b,c), the amplitude of the diurnal cycle is remarkably similar for all regions and the amplitude never varies by more than about $20 \%$ for any region. A peak for both types of features occurs in the early morning; PFs with ice scattering have a second, smaller peak in the afternoon. This second peak is especially prominent in the central Pacific and SPCZ areas. This afternoon peak in the SPCZ is noted in the IR observations of Janowiak et al. (1994). This peak may suggest that the afternoon destabilization mechanism suggested by Chen and Houze (1997) may be occurring in calm, warm open ocean areas; however, the SPCZ hardly represents a calm ocean area like the west Pacific warm pool to the northwest. These small- to medium-sized systems that start as individual cumulonimbi may grow, merge, and produce outflow boundaries that, later at night, form MCSs.

Oceanic MCSs' diurnal cycle of rainfall have a higher amplitude by region than the other feature types. Every region (except the SPCZ) has a single peak between 0100 and 1100 LT. Interestingly, the SPCZ has a sec- ondary peak around noon, which may again coincide with the Janowiak et al. (1994) observations. Some regions peak before 0600 LT (SPCZ, east Pacific, Indian Ocean, central Pacific), whereas some peak after 0600 LT (Atlantic Ocean, southwest Pacific, northwest Pacific). Every region has below-mean rainfall amplitudes between 1500 and 2300 LT, illustrating the Tropicswide oceanic afternoon minimum in rainfall from MCSs. Note that the diurnal peak in rainfall from PFs without ice scattering occurs between 0100 and 0300 LT, from PFs with ice scattering between 0300 and 0500 LT, and MCSs for most regions between 0500 and 1100 LT. This highlights a slow upscale growth process occurring overnight over the ocean. While PFs over the ocean are omnipresent in all regions, it appears that a growth process beginning with the smallest features around sunset may occur in all regions.

Over land regions, the diurnal amplitude of rainfall is, as shown before, much stronger for PFs with and without ice scattering (Figs. 13e,f). Tropical and subtropical Africa, and tropical South America have the strongest amplitudes, with the African regions having the strongest amplitudes in the category with ice scattering (around 1500 LT), while tropical South America has the highest peak in PFs without ice scattering (peaking earlier around 1500 LT). The Maritime Continent region (containing both land and ocean areas) diurnal 

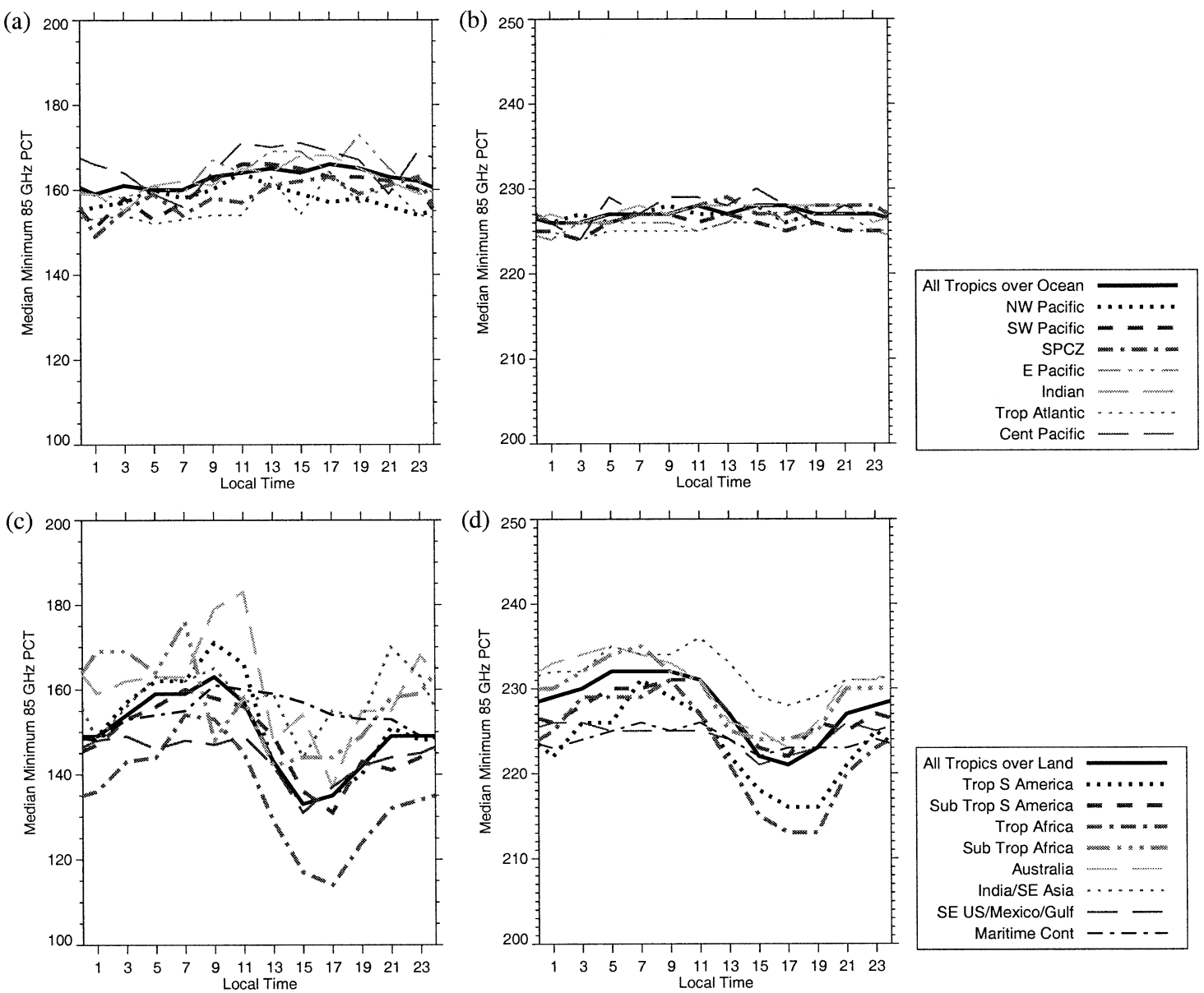

FIG. 14. The diurnal cycle of regional median minimum 85-GHz PCTs of PFs by type: (a) PFs with MCSs over ocean, (b) PFs with ice scattering over ocean, (c) PFs with MCSs over land, (d) PFs with ice scattering over land. The legends at right correspond to the row of figures to their left.

cycle is comparable to the oceanic regions for non-MCS features, except for a small amplitude afternoon peak corresponding to the afternoon convective development over the islands (see Fig. 3). Interestingly, PFs without ice scattering amplitudes over the southeast United States-Mexico-Gulf of Mexico region appear very similar to the Maritime Continent's, while features with ice scattering amplitudes appear more continental. This is due to the strong diurnal cycle over the Sierra Madre, Florida, and other land areas within the region.

MCS phases and amplitudes over land areas vary significantly. Subtropical regions generally contain peaks in the afternoon and before midnight (subtropical Africa, Australia, India and Southeast Asia, and the southeast United States-Mexico-Gulf of Mexico). Tropical South America and tropical Africa have peaks between midnight and 0300 LT. India/Southeast Asia has a second peak around 0500 LT. The Maritime Continent's peak occurs around 0700 LT, coincident with the peak in the southwest Pacific region. Note the strong peak in subtropical South American MCS rainfall around 0700 LT. Large, intense MCSs occur over Argentina and Uru- guay preferentially in the hours around sunrise there during the warm season (Yorty 2001). While all continental regions have an afternoon peak (1300-1500 LT) in non-MCS features that decreases below-mean values by sunset, only subtropical areas have a corresponding maximum in MCS rainfall in the evening. Tropical areas' MCS rainfall (tropical South America and Africa) continues until well after midnight. Africa's MCS rainfall rises to a constant level between 1900 and 0500 LT, while South American MCS rainfall has a peak around 0100 LT. These regional differences in the diurnal cycle over land implore further investigation into their controlling factors, whether they are related to surface, environmental, or topographic forcing (e.g., McCollum et al. 2000).

\section{c. Regional diurnal cycles of convective intensity}

Figures 14 and 15 plot the median values of the two parameters used to estimate the peak convective vigor of PFs presented in section 5. Regional median minimum $85-\mathrm{GHz}$ PCTs for PFs with MCSs and with ice 

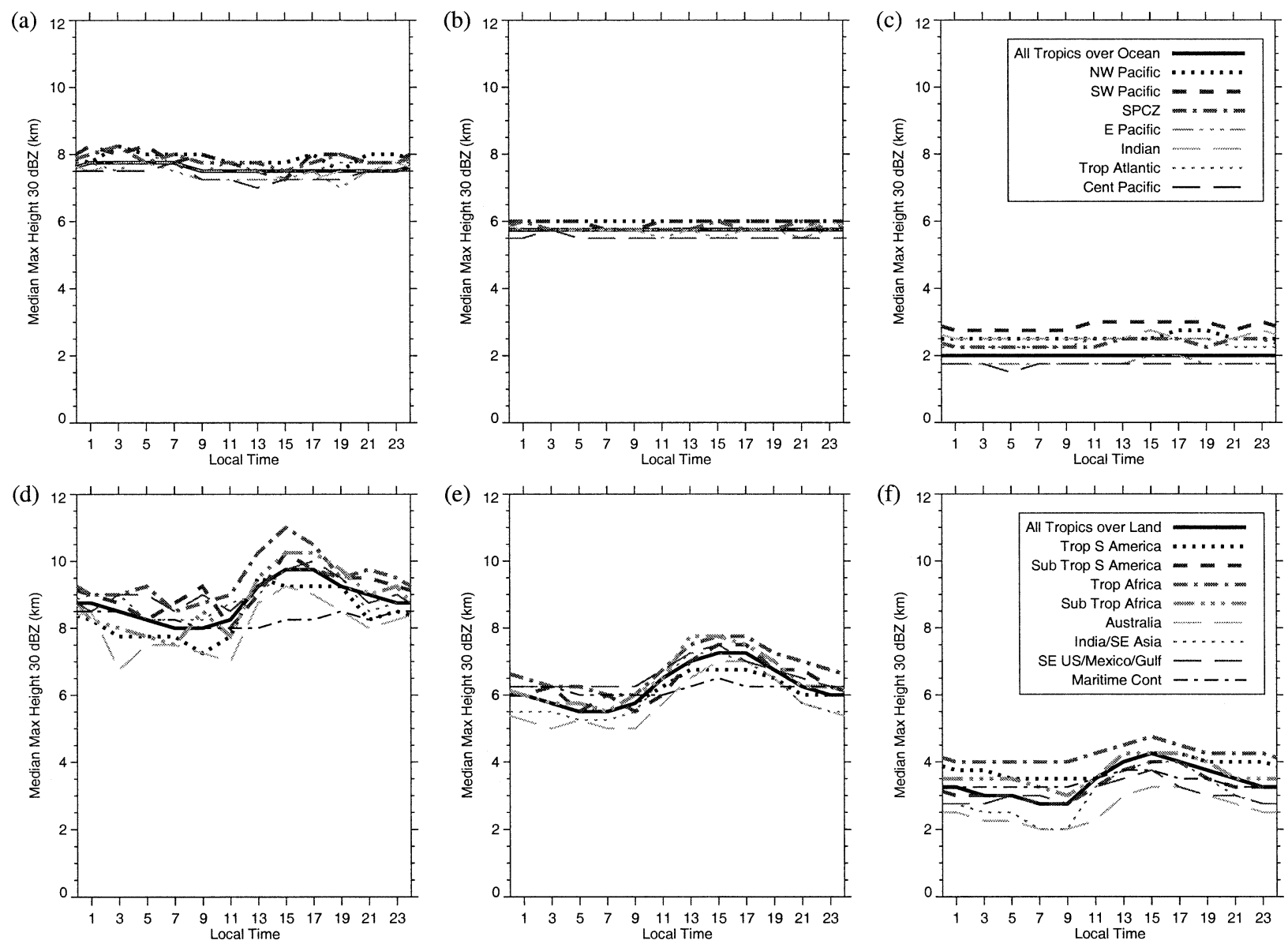

FIG. 15. The diurnal cycle of regional median maximum 30-dBZ echo-top heights of PFs by type: (a) PFs with MCSs over ocean, (b) PFs with ice scattering over ocean, (c) PFs without ice scattering over ocean, (d) PFs with MCSs over land, (e) PFs with ice scattering over land, and (f) PFs without ice scattering over land. The legends at right correspond to the row of figures to their left.

scattering are plotted in Fig. 14 (features without ice scattering show no significant regional diurnal variation as shown by Fig. 8). With the sample size of PFs, the mean $90 \%$ confidence interval of the median minimum $85-\mathrm{GHz}$ PCT for PFs with ice scattering, and with an MCS are \pm 1.1 and $3.9 \mathrm{~K}$, respectively. Over the ocean, PFs with ice scattering (Fig. 14b) have practically no significant diurnal and regional variation. MCSs over the ocean (Fig. 14a) have a slight tendency for more intense ice scattering in the early morning.

The PFs with ice scattering over most land regions (Fig. 14d) have significantly depressed minimum 85$\mathrm{GHz}$ PCTs in the afternoon, with mixed regions having only slight depressions in the afternoon and evening hours. Features containing MCSs (Fig. 14c) also have a significant afternoon maximum in $85-\mathrm{GHz}$ indicated convective intensity, with tropical Africa and the southeast United States-Mexico-Gulf of Mexico regions contain some of the most intense ice scattering signatures from MCSs. Again, the Maritime Continent shows a more oceanic signature.

Similarly, median maximum heights of the $30-\mathrm{dBZ}$ echo are plotted in Fig. 15 except PFs without ice scattering appear here (Figs. 15c,f), the mean 90\% confidence interval $\pm 0.02,0.05$, and $0.30 \mathrm{~km}$ for PFs without ice scattering, with ice scattering, and with MCSs, respectively. Again, oceanic features have little significant diurnal intensity variation (Figs. 15a-c). While for 85$\mathrm{GHz}$ comparisons, PFs without ice scattering had insignificant variations among oceanic regions, here the southwest Pacific region has the most intense radar signature, while the central Pacific has the least. These differences become less considering the other two feature types (Figs. 15a,b). There is a slight tendency for features with MCSs (Fig. 15a) to have roughly $500 \mathrm{~m}$ higher median $30-\mathrm{dBZ}$ heights in the predawn hours over the ocean.

Over land (Figs. 15d-f), all three types of features have a significant diurnal intensity maximum in the afternoon. The Maritime Continent region again is an obvious outlier here, although there is a slight perturbation in $30-\mathrm{dBZ}$ heights in the afternoon in non-MCS features corresponding with the afternoon development of convection over the islands (see Fig. 2). The timing of the 
maximum is consistent among all land regions and all feature types, as well as the prominence of tropical Africa and Australia having the most intense and weakest radar profiles according to all three feature types, respectively.

\section{Summary}

The diurnal cycle of remotely sensed rainfall and convective intensity is analyzed from three years of data from the TRMM PR and TMI. The PR's 2A25 radar reflectivity-rain-rate relationship offers more direct remote sensing estimates of near-surface rainfall than other methods (IR or microwave brightness temperatures), offering quantitative instantaneous estimates of surface rainfall amount, convective-stratiform portioning, and yielding proxies for convective intensity. Observations from the PR and TMI between $\pm 36^{\circ}$ latitude are collocated, and grouped into individual storms, or so-called precipitation features (PFs) larger than $75 \mathrm{~km}^{2}$ in size using the algorithm outlined in Nesbitt et al. (2000). The algorithm classifies the storm into three types: MCSs, features with TMI $85-\mathrm{GHz}$ PCT $\leq 250 \mathrm{~K}$ not meeting MCS size or intensity criteria (convective clouds with significant optical depths of ice aloft), and features without $85-\mathrm{GHz}$ PCT $\leq 250 \mathrm{~K}$ (small convective features or "warm rain"). Diurnal composites of the rainfall and other properties of the PFs by storm type yield a tool to examine their daily variation. Sampling from the low earth-orbiting TRMM satellite (with its $215-\mathrm{km}$ PR swath) must be taken into account, in this study only 3-yr composites over all tropical ocean and land areas are examined, regional investigations are made at no less than $10^{\circ}$ grids for $3 \mathrm{yr}$. These composites are used to examine the large-scale bulk characteristics of the tropical diurnal cycle.

Rainfall over the oceans has a significant diurnal cycle (varying by $30 \%$ ) that peaks in the early morning to predawn hours, with a minimum in the late afternoon. This rainfall maximum is due to increased rainfall contributions from MCSs; diurnal rainfall variations from non-MCS features remain minimal. These trends are similar among all the ocean regions considered in this study. The increased number of MCSs observed in the early morning hours combines with slightly increasing median areas, leading to this rainfall peak.

Total conditional rain rates, convective-stratiform portioning, and rain rates remain constant over ocean, conveying that this predawn rainfall maximum is not due to increased rain rates within the systems sampled. Thus, this leads the authors to clarify previous theories on diurnal cycle mechanisms that may suggest that rain rates are heavier during the observed predawn maximum of oceanic rainfall. This study sees little enhancement in the observed convective intensity and conditional rain rates that correspond with the observed early morning maximum in rainfall (in agreement with the results of Dai 2001). The increased number of systems observed during the predawn hours suggest that over the ocean, the nocturnal environment is simply more favorable for cloud systems to grow to become MCSs, or for MCSs to live longer (snapshots from TRMM do not allow the direct observations of the system's life cycle).

Over land, all feature types contribute to an afternoon maximum in precipitation (which has a magnitude variation of $125 \%$ ), but MCS rainfall peaks in the early morning. The number of systems, conditional rainfall rates, and convective intensities of features without and with ice scattering respond strongly to afternoon heating. An increase in conditional rain rates in non-MCS systems, in particular, corresponds to an afternoon peak in convective rain fraction. This result differs from the rain gauge analysis of Dai et al. (1999); this is attributed to different areas of study and sampling differences by instantaneous (this study) versus hourly rain measurements (used in Dai et al.'s study). MCSs over land also see an increase in conditional rain rates and convective intensities in the afternoon; however, their persistence and increasing areas throughout the nighttime lead to a near-midnight maximum in MCS rainfall (Laing and Fritsch 1997). While the timing of rainfall from features with and without ice scattering was in phase among regions, rainfall amplitudes varied considerably. Both the timing and amplitude of MCS regional rainfall also varies significantly, with subtropical $\left(30^{\circ}-35^{\circ}\right.$ latitude) MCS rainfall peaks during the evening; tropical area MCS rainfall peaks tend to be after midnight. These differences are likely due to the varying dynamical and thermodynamical environments in which these storms form.

The mechanisms of the rainfall peak associated with overland afternoon instability are well understood and observed. However, the diurnal cycle of rainfall associated with MCSs remains poorly understood and modeled. This results from our incomplete understanding of land surface fluxes, effects of nearby topography, and their relation to convective processes.

The eventual goal of this research is to provide a database that may facilitate the evaluation of cloud resolving models (CRMs) on a statistical basis as well as the performance of general circulation models (GCMs), such that our understanding of the diurnal cycle (and the climate system as a whole) may be improved. Matching the sampling of TRMM with that of numerical model simulations will be a major challenge of this effort. The accumulation of additional data from TRMM and the planned Global Precipitation Mission (GPM) will allow a more comprehensive regional and seasonal remote sensing evaluation of rainfall and convective intensity.

Acknowledgments. TRMM is a project cosponsored by NASA and NASDA, the Japanese space agency. The authors would like to thank Ramesh Kakar for his continued support of TRMM science. Thanks to Baike Xi for her valuable data-processing assistance. The follow- 
ing have contributed to the development of the PF algorithm in addition to the authors: Dan Cecil, Rick Toracinta, David B. Wolff, and Chris West. Thanks to Dan Cecil, Dennis Boccippio, and the comments of two anonymous reviewers who greatly improved the content of this manuscript. Special thanks go to Erich Stocker and John Kwiatkowski and the rest of the TRMM Science Data and Information System (TDSIS) at NASA Goddard Space Flight Center, Greenbelt, Maryland, for providing the TRMM data used in this study. CPC hourly precipitation data provided by the NOAA-CIRES Climate Diagnostics Center, Boulder, Colorado, from their Web site (http://www.cdc.noaa.gov). This research was supported by NASA TRMM science Grants NAG59717 and NAG5-10682; SWN was supported by the NASA Earth System Science Graduate Fellowship Grant NGT5-30423.

\section{REFERENCES}

Adler, R. F., G. J. Huffman, D. T. Bolvin, S. Curtis, and E. J. Nelkin, 2000: Tropical rainfall distributions determined using TRMM combined with other satellite and rain gauge information. $J$. Appl. Meteor., 39, 2007-2023.

Albright, M. D., E. R. Recker, R. J. Reed, and R. Dang, 1985: The diurnal variation of deep convection and inferred precipitation in the central tropical Pacific during January-February 1979. Mon. Wea. Rev., 113, 1663-1680.

Biggerstaff, M. I., and S. A. Listemaa, 2000: An improved scheme for convective/stratiform echo classification using radar reflectivity. J. Appl. Meteor., 39, 2129-2150.

Boccippio, D. J., S. J. Goodman, and S. Heckman, 2000: Regional differences in tropical lightning observations. J. Appl. Meteor., 39, 2231-2248.

Brier, G. W., and J. S. Simpson, 1969: Tropical cloudiness and precipitation related to pressure and tidal variations. Quart. J. Roy. Meteor. Soc., 95, 120-147.

Chang, A. T. C., L. S. Chiu, and G. Yang, 1995: Diurnal cycle of oceanic precipitation from SSM/I data. Mon. Wea. Rev., 123, 3371-3380.

Chen, S. S., and R. A. Houze Jr., 1997: Diurnal variation and lifecycle of deep convective systems over the Pacific warm pool. Quart. J. Roy. Meteor. Soc., 123, 357-388.

Cox, S. K., and K. T. Griffith, 1979: Estimates of radiative divergence during Phase III of the GARP Atlantic Tropical Experiment: Part II. Analysis of Phase III results. J. Atmos. Sci., 36, 586-601.

Dai, A., 2001: Global precipitation and thunderstorm frequencies. Part II: Diurnal variations. J. Climate, 14, 1112-1128.

—_, F. Giorgi, and K. E. Trenberth, 1999: Observed and modelsimulated diurnal cycles of precipitation over the contiguous United States. J. Geophys. Res., 104, 6377-6402.

Del Genio, A. D., and W. Kovari, 2002: Climatic properties of tropical precipitating convection under varying environmental conditions. J. Climate, 15, 2597-2615.

Dudhia, J., 1989: Numerical study of convection observed during the Winter Monsoon Experiment using a mesoscale two-dimensional model. J. Atmos. Sci., 46, 3077-3107.

Garreaud, R. D., and J. M. Wallace, 1997: The diurnal march of convective cloudiness over the Americas. Mon. Wea. Rev., 125, $3157-3171$

Gray, W. M., and R. W. Jacobson Jr., 1977: Diurnal variation of deep cumulus convection. Mon. Wea. Rev., 105, 1171-1188.

Hall, T. J., and T. H. Vonder Haar, 1999: The diurnal cycle of West Pacific deep convection and its relation to the spatial and temporal variation to tropical MCSs. J. Atmos. Sci., 56, 3401-3415.

Hartmann, D. L., H. H. Hendon, and R. A. Houze Jr., 1984: Some implications of the mesoscale circulations in tropical cloud clusters for large-scale dynamics and climate. J. Atmos. Sci., 41, $113-121$.

Higgins, R. W., J. E. Janowiak, and Y.-P. Yao, 1996: A gridded hourly precipitation data base for the United States (1963-1993). NCEP/ Climate Prediction Center Atlas 1, NOAA, $47 \mathrm{pp}$.

Houze, R. A., Jr., 1993: Cloud Dynamics. Academic Press, 573 pp. , 1997: Stratiform precipitation in regions of convection: A meteorological paradox? Bull. Amer. Meteor. Soc., 78, 2179-2196.

Iguchi, T., T. Kozu, R. Meneghini, J. Awaka, and K. Okamoto, 2000 Rain-profiling algorithm for the TRMM precipitation radar. $J$. Appl. Meteor., 39, 2038-2052.

Imaoka, K., and R. W. Spencer, 2000: Diurnal variation of precipitation over the tropical oceans observed by TRMM/TMI combined with SSM/I. J. Climate, 13, 4149-4158.

Janowiak, J. E., P. A. Arkin, and M. Morrissey, 1994: An examination of the diurnal cycle in oceanic tropical rainfall using satellite and in situ data. Mon. Wea. Rev., 122, 2296-2311.

Kraus, E. B., 1963: The diurnal precipitation change over the sea. $J$. Atmos. Sci., 20, 551-556.

Kummerow, C., W. Barnes, T. Kozu, J. Shiue, and J. Simpson, 1998: The Tropical Rainfall Measuring Mission (TRMM) sensor package. J. Atmos. Oceanic Technol., 15, 809-817.

— suring Mission (TRMM) after two years in orbit. J. Appl. Me teor., 39, 1965-1982.

Laing, A. K., and M. G. Fritsch, 1997: The global population of mesoscale convective complexes. Quart. J. Roy. Meteor. Soc., 123, 389-405.

Lieberman, R. S., C. B. Leovy, B. A. Boville, and B. P. Briegleb, 1994: Diurnal heating and cloudiness in the NCAR Community Climate Model (CCM2). J. Climate, 7, 869-889.

Lin, X., D. A. Randall, and L. D. Fowler, 2000: Diurnal variability of the hydrologic cycle and radiative fluxes: Comparisons between observations and a GCM. J. Climate, 13, 4159-4179.

Lindzen, R. S., 1978: Effect of daily variations of cumulonimbus activity on the atmospheric semidiurnal tide. Mon. Wea. Rev., 106, 526-533.

Liu, C., and M. W. Moncrieff, 1998: A numerical study of the diurnal cycle of tropical oceanic convection. J. Atmos. Sci., 55, 2329 2344.

Malkus, J. S., 1964: Convective processes in the tropics. Proc. Symp. on Tropical Meteorology, Rotorua, New Zealand, New Zealand Meteorological Service, 247-277.

Mapes, B. E., and Robert A. Houze Jr., 1993: Cloud clusters and superclusters over the oceanic warm pool. Mon. Wea. Rev., 121, $1398-1416$.

McAnelly, R. L., and W. R. Cotton, 1989: The precipitation life cycle of mesoscale convective complexes over the central United States. Mon. Wea. Rev., 117, 784-808.

McCollum, J. R., A. Gruber, and M. B. Ba, 2000: Discrepancy between gauges and satellite estimates of rainfall in equatorial Africa. J. Appl. Meteor., 39, 666-679.

McGarry, M. M., and R. J. Reed, 1978: Diurnal variations in convective activity and precipitation during Phases II and III of GATE. Mon. Wea. Rev., 106, 101-113.

Mohr, K. I., and E. J. Zipser, 1996: Mesoscale convective systems defined by their $85-\mathrm{GHz}$ ice scattering signature: Size and intensity comparison over tropical oceans and continents. Mon. Wea. Rev., 124, 2417-2437.

_ _ J. S. Famiglietti, and E. J. Zipser, 1999: The contribution to tropical rainfall with respect to convective system type, size, an intensity estimated from the $85-\mathrm{GHz}$ ice-scattering signature. $J$. Appl. Meteor., 38, 596-606.

Nesbitt, S. W., E. J. Zipser, and D. J. Cecil, 2000: A census of precipitation features in the Tropics using TRMM: Radar, ice scattering, and lightning observations. J. Climate, 13, 4087-4106.

Oki, T., and K. Musiake, 1994: Seasonal change of the diurnal cycle of precipitation over Japan and Malaysia. J. Appl. Meteor., 33, $1445-1463$. 
Petersen, W. A., and S. A. Rutledge, 2001: Regional variability in tropical convection: Observations from TRMM. J. Climate, 14, 3566-3586.

,-- , and R. E. Orville, 1996: Cloud-to-ground lightning observations from TOGA COARE: Selected results and lightning location algorithms. Mon. Wea. Rev., 124, 602-620.

Randall, D. A., Harshvardhan, and D. A. Dazlich, 1991: Diurna variability of the hydrologic cycle in a general circulation model. J. Atmos. Sci., 48, 40-62.

Reed, R. J., and J. D. Jaffe, 1981: Diurnal variation of summer convection over West Africa and the tropical eastern Atlantic during 1974 and 1978. Mon. Wea. Rev., 109, 2527-2534.

Rickenbach, T. M., 1996: Convection in TOGA COARE: Horizontal scale, morphology, and rainfall production. Ph.D. dissertation, Dept. of Atmospheric Science, Colorado State University, 154 pp.

Sherwood, S. C., and R. Wahrlich, 1999: Observed evolution of tropical deep convective events and their environment. Mon. Wea. Rev., 127, 1777-1795.

Short, D. A., and J. M. Wallace, 1980: Satellite-inferred morning-toevening cloudiness changes. Mon. Wea. Rev., 108, 1160-1169.

— precipitation over the tropical oceans. J. Climate, 13, 41074124.

- P. A. Kucera, B. S. Ferrier, J. C. Gerlach, S. A. Rutledge, and O. W. Thiele, 1997: Shipboard radar rainfall patterns within the TOGA COARE IFA. Bull. Amer. Meteor. Soc., 78, 2817-2836.

Silva Dias, P. L., J. P. Bonatti, and V. E. Kousky, 1987: Diurnally forced tropical tropospheric circulation over South America. Mon. Wea. Rev., 115, 1465-1478.

Spencer, R. W., H. M. Goodman, and R. E. Hood, 1989: Precipitation retrieval over land and ocean with the SSM/I: Identification and characteristics of the scattering signal. J. Atmos. Oceanic Technol., 6, 254-273.
Sui, C.-H., K.-M. Lau, Y. N. Takayabu, and D. A. Short, 1997: Diurnal variations in tropical oceanic cumulus convection during TOGA COARE. J. Atmos. Sci., 54, 639-655.

Tao, W.-K., S. Lang, J. Simpson, C.-H. Sui, B. Ferrier, and M.-D. Chou, 1996: Mechanisms of cloud-radiation interaction in the Tropics and midlatitudes. J. Atmos. Sci., 53, 2624-2651.

Toracinta, E. R., D. J. Cecil, E. J. Zipser, and S. W. Nesbitt, 2002: Radar, passive microwave, and lightning characteristics of precipitating systems in the Tropics. Mon. Wea. Rev., 130, $802-$ 824.

Vivekanandan, J., J. Turk, and V. N. Bringi, 1991: Ice water path estimation and characterization using passive microwave radiometry. J. Appl. Meteor., 30, 1407-1421.

Wallace, J. M., 1975: Diurnal variations in precipitation and thunderstorm frequency over the conterminous United States. Mon. Wea. Rev., 103, 406-419.

Webster, P. J., and G. L. Stephens, 1980: Tropical upper-tropospheric extended clouds: Inferences from winter MONEX. J. Atmos. Sci., 37, 1521-1541.

Williams, M., and R. A. Houze Jr., 1987: Satellite-observed characteristics of winter monsoon cloud clusters. Mon. Wea. Rev., 115, 505-519.

Xu, K.-M., and D. A. Randall, 1995: Impact of interactive radiative transfer on the macroscopic behavior of cumulus ensembles. Part II: Mechanisms for cloud-radiation interactions. J. Atmos. Sci., 52, 800-817.

Yang, G.-Y., and J. Slingo, 2001: The diurnal cycle in the Tropics. Mon. Wea. Rev., 129, 784-801.

Yorty, D. P., 2001: Extreme convection observed by the Tropical Rainfall Measuring Mission. M.S. thesis, Dept. of Meteorology, University of Utah, $114 \mathrm{pp}$.

Zudiema, P., 2003: Convective clouds over the Bay of Bengal. Mon. Wea. Rev., 131, 616-634. 